\title{
LAS PIEDRAS VERDES DE TLAILOTLACAN Teotihuacán y sus Tradiciones Tecnológicas
}

\section{THE GREENSTONES FROM TLAILOTLACAN Teotihuacan, and its Technological Traditions}

\section{Angy Jimena Domínguez Domínguez ${ }^{1}$}

ajdd-10@hotmail.com

\section{RESUMEN}

En el presente artículo se presenta el análisis mineralógico y tecnológico de toda la lapidaria verde de Tlailotlacan. Se muestran las distintas técnicas arqueométricas empleadas para el análisis químico-mineralógico: Fluorescencia de Luz Ultravioleta (UV), Espectroscopía por dispersión de Energía de Rayos X (EDS) y Espectroscopía Micro-Raman ( $\mu$ Raman) para la identificación de la materia prima y sus posibles yacimientos. Mientras que las aplicadas para el análisis tecnológico fueron Arqueología Experimental y Microscopía Electrónica de Barrido para huellas de manufactura para establecer las tradiciones tecnológicas lapidarias presentes en esta colección procedente de Tlailotlacan.

Palabras clave: Minerales, tecnología, manufactura, tradiciones.

\footnotetext{
${ }^{1}$ Discente, Posgrado en Estudios Mesoamericanos, Universidad Nacional Autónoma de México.
} 


\section{ABSTRACT}

This article presents the mineralogical and technological analysis of the entire greenstones of Tlailotlacan. The archaeometric techniques used for mineralogical analysis were Ultraviolet Light Fluorescence (UVF), Electron Microprobe Spectroscopy (EDS) and Micro-Raman Spectroscopy ( $\mu$ Raman) for the identification of the raw material and its possible deposits. While the techniques applied for traceological analysis were Experimental Archaeology and Scanning Electron Microscopy to establish the lapidary traditions presented in this collection from Tlailotlacan.

Keywords: Minerals, technology, manufacture, traditions.

\section{CONTEXTO DE LA INVESTIGACIÓN}

Las evidencias materiales son la prueba de los intercambios de objetos e ideas que se llevaron a cabo entre distintas regiones y cuyas redes de intercambio fueron controladas por los centros de poder, en el caso del Altiplano durante el Clásico, fue Teotihuacán quien controló dichos circuitos (BRANIFF, 1995; FAHMEL, 1995; ORTEGA, 2014: 3). Otra de las características más destacables de la metrópoli fue su carácter multiétnico gracias a sus múltiples contactos comerciales, religiosos, económicos y políticos, entre otros. Algunas de las regiones con las que mantuvo contacto a lo largo de su existencia fueron Oaxaca, la Costa del Golfo, Guerrero, Occidente, el Bajío de México y Las Tierras Bajas Mayas (ORTEGA, 2014: 3).

Una forma de aproximarnos y entender cómo y porqué se dieron estos contactos es a través de la identificación de los estilos o tradiciones tecnológicas presentes en los artefactos hallados en los vecindarios de la urbe teotihuacana. En el presente 
artículo se expone el análisis tecnológico de toda la lapidaria verde de Tlailotlacan la cual, forma un cuerpo de 26 artefactos (Tabla 1). El objetivo es presentar las distintas técnicas arqueométricas a las que se recurrió para realizar el estudio de estas piezas y poder identificar: 1) la materia prima y sus posibles yacimientos y 2) las tradiciones tecnológicas lapidarias presentes en Tlailotlacan.

\section{TRADICIÓN Y ESTILO TECNOLÓGICO}

Cada cultura o grupo social tiene una forma particular de manufacturar sus objetos y de transmitirla de una generación a otra. Esto incluye la manera de elaborar piezas, el modo sistemático en que los artesanos determinan secuencias de manufactura a costa de otros dentro de un espacio y tiempo determinados (SACKETT, 1977; CARR Y NEITZEL, 1995; MELGAR, 2014: 12-13). Por esta razón, uno de los objetivos de la arqueología es identificar tanto la tradición tecnológica como temporal de los artefactos dejados por sociedades pretéritas "a partir de rasgos diagnósticos, con el fin de rastrear su origen geográfico, cultural o cronológico" (MELGAR, 2014: 12). Para lo anterior, en este texto se retoman dos conceptos importantes el de "estilo tecnológico" y "tradición tecnológica".

Cuando los objetos poseen rasgos reconocibles es fundamental comprender las convenciones estilísticas que permitan asociarlos a una cultura o grupo étnico determinado, sin embargo, esta aproximación no es suficiente, ya que algunos de estos rasgos pueden ser similares en diferentes culturas, lo que puede derivar en un error cuando se trata de identificar el origen de manufactura de los artefactos 
(MONTERROSA, 2018: 16). Otro problema es cuando se cuenta con objetos sin iconografía o con formas geométricas no definidas que permitan asignar una pertenencia tanto cultural como cronológica (MONTERROSA, 2018: 14). Lo anterior no puede ser resuelto desde una perspectiva visual o morfológica de las piezas, sino a través del análisis tecnológico más profundo de los materiales, por lo cual resulta imprescindible definir el estilo desde un enfoque tecnológico.

El estilo tecnológico se refiere a la elección y repetición sistemática y regulada de la forma en que se hacen las cosas desechando otras, lo que puede cambiar más fácilmente en comparación con la tradición tecnológica y, corresponden a un tiempo corto y una distribución espacial restringida (WILLEY Y PHILLIPS, 1958; SACKETT, 1977; CONKEY, 1978: 66-67; MELGAR, 2014: 13). Lo anterior se traduce en las técnicas empleadas en la elaboración de los artefactos, su tratamiento estilístico, los cuales son identificables y diferenciables para cada cultura, grupo étnico o estilo artístico (CONKEY, 1978: 66-67) dentro de un espacio y periodo de tiempo determinados.

Por otro lado, la tradición tecnológica hace referencia a la persistencia de un conjunto de tecnologías, con una continuidad temporal y espacial más amplia que la anterior, por lo que se habla de tradiciones regionales (WILLEY Y PHILLIPS, 1958: 35; PÉREZ, 2016: 20-21). Aunado a esto, cabe agregar que es resistente al cambio y la innovación tecnológica debido a que depende de factores tanto políticos como económicos, simbólicos y/o ideológicos, por eso se considera un medio de 
integración social (MELGAR, 2014: 13; MONTERROSA, 2018: 26; WILLEY Y PHILLIPS, 1958: 37).

En otras palabras, una tradición tecnológica se refiere a la forma en que se hacen las cosas, de manera continua a lo largo de un prolongado periodo de tiempo, donde se repiten tecnologías complejas o sencillas e incluye uno o varios estilos que pueden restringirse a una técnica de elaboración y/o forma de decoración. Lo anterior se repite sistemáticamente de una generación a otra. (MELGAR, 2014: 13; SACKETT, 1977: 371-375).

Ambos conceptos anteriores se complementan entre sí para integrar la combinación de datos culturales, espaciales y temporales. De este modo, la tradición tiene una:

(...) perspectiva diacrónica, donde la tecnología presenta una profundidad temporal de larga duración y una amplia distribución espacial a nivel regional o de área cultural; mientras que el estilo tiene un enfoque de tipo sincrónico, ya que su escala temporal y espacial es mucho menor. (MELGAR, 2014: 13-14).

Cuando existe la presencia de estilos similares en distintas regiones contemporáneas y relacionadas entre sí, se puede hablar de un horizonte estilístico, pero, si éste se mantiene por un tiempo mayor se puede hablar de la continuidad de una tradición regional (WILLEY Y PHILLIPS, 1958: 35; PÉREZ, 2016: 20-21). Es importante tener en cuenta que la tradición y el estilo van más allá de la decoración y diseños impresos en los artefactos pues también se debe tomar en 
cuenta la imitación de las piezas por grupos ajenos a los de la región o área de origen. Por eso es trascendental la inclusión de la parte tecnológica al estilo ya que permite profundizar en las formas en que una cultura se expresa materialmente hablando y qué tanto plasma en los materiales su "marca de fábrica" o identidad (WOBST, 1977: 321).

\section{LAS PIEDRAS VERDES DE TLAILOTLACAN}

Tlailotlacan, también conocido como "Barrio Oaxaqueño", denominado así por las evidencias halladas que son similares a las localizadas en Valles Centrales de Oaxaca (ORTEGA, 2014: 6), por ejemplo, la cerámica, la arquitectura y los patrones funerarios; lo que lleva a pensar que probablemente fue fundado por un grupo de inmigrantes zapotecas (SPENCE, 1992).

Dicho vecindario se localiza a $3.27 \mathrm{~km}$. al oeste de la antigua ciudad de Teotihuacán, tomando como referencia la Pirámide del Sol (Figura 1). Tiene una superficie de alrededor de 25,000 m2 distribuido en por lo menos 14 conjuntos arquitectónicos de los cuales, 12 han sido parcialmente excavados hasta el día de hoy (ORTEGA, 2014: 6). Fue un asentamiento que se estableció aproximadamente en el año 150 d. C., es decir, durante la fase Miccaotli (150-200 d. C.) y continuó ocupado alrededor de 300 a 400 años (RATTRAY, 1973: 4). De acuerdo con Michael Spence (1992: 59) la población de este sector urbano pudo haber llegado a los 600 o 700 individuos. 


\section{Clio Arqueológica 2020, V35N2, p.29-77, DOMINGUEZ}

DOI: 10.20891/clio.V35V2p29-77

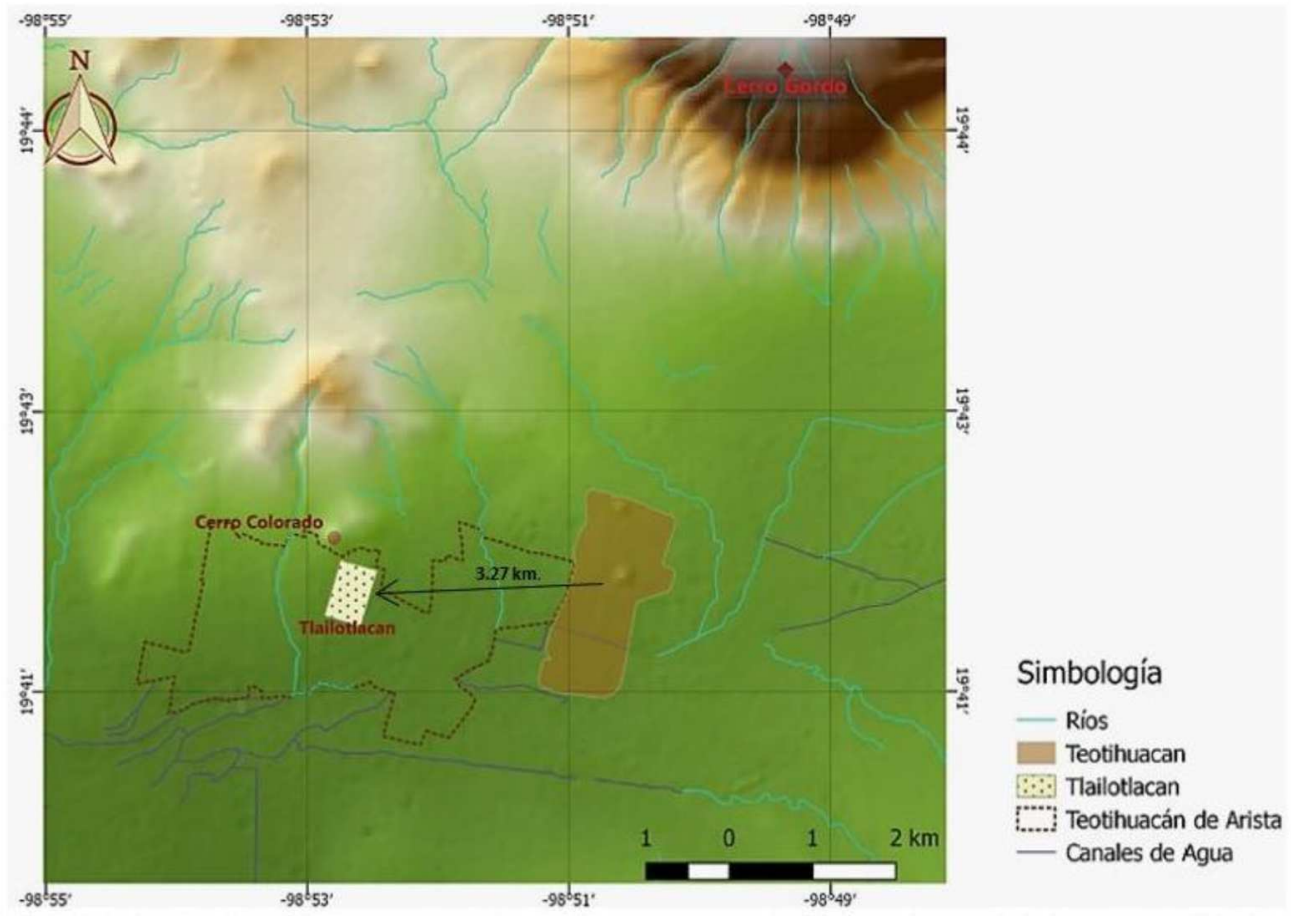

Figura 1: Ubicación de Tlailotlacan (Elaborado por Angy Domínguez).

La colección de piedras verdes procedentes de este vecindario consta de 26 objetos: once cuentas discoidales y esféricas, una prótesis dental, un pectoral inciso, cuatro figurillas antropomorfas, una aplicación discoidal, cuatro esferas, ${ }^{2}$ una placa trapezoidal, un pulidor, tres fragmentos que presentan trabajo y un trozo de materia prima (Tabla 1).

\footnotetext{
${ }^{2}$ Una de las esferas no es color verde, pero se ha integrado a este cuerpo como objeto de piedra verde debido a su composición mineralógica.
} 


\section{Clio Arqueológica 2020, V35N2, p.29-77, DOMINGUEZ DOI: 10.20891/clio.V35V2p29-77}

De los conjuntos que conforman Tlailotlacan, en cinco se han encontrado los objetos enlistados antes (Tabla 1 y Figura 2), de esos cinco, tres tienen carácter administrativo (TL6, TL1 y TL11) y dos un carácter doméstico (TL7 y TL9), lo cual se ha inferido a partir de la arquitectura y otras características (véase ORTEGA, 2014 y DOMÍNGUEZ, 2015).

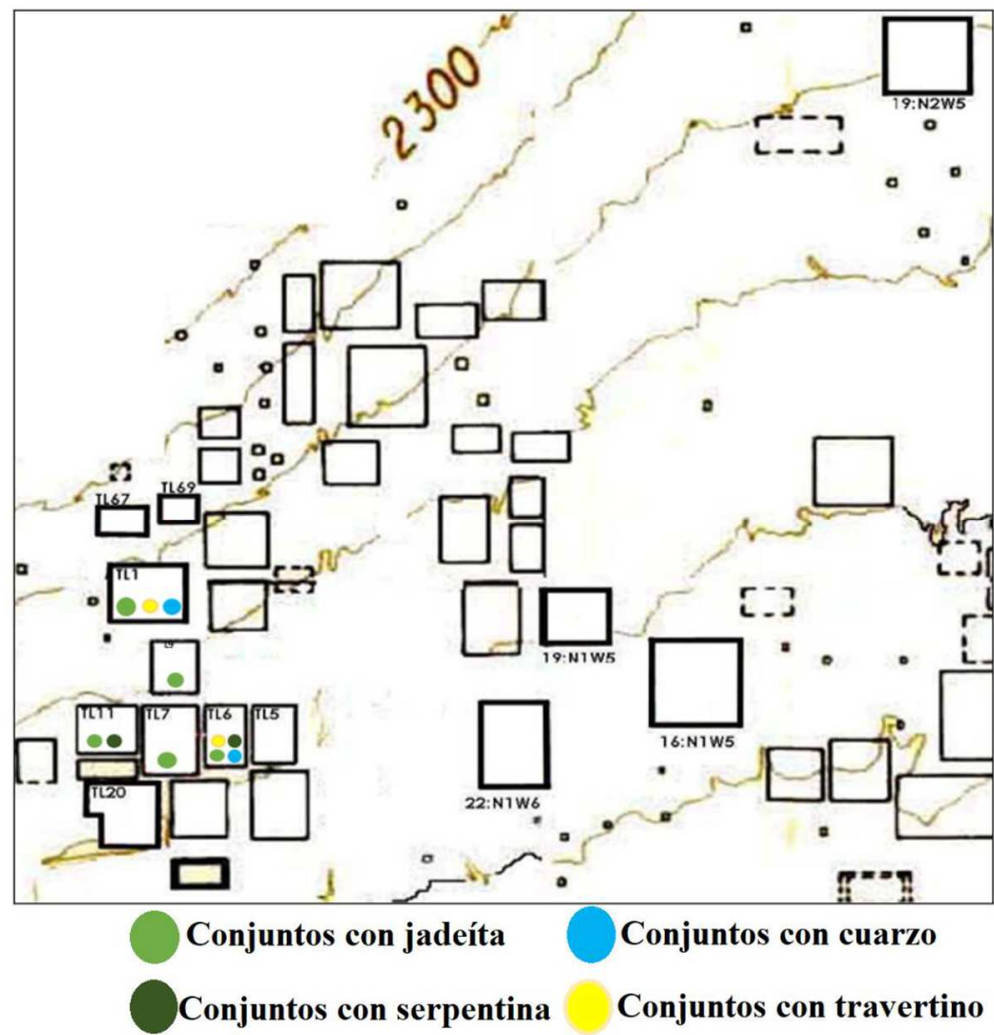

Figura 2. Plano de ubicación de los diferentes conjuntos arquitectónicos que conforman Tlailotlacan y distribución de los objetos de piedra verde (Plano tomado de MILLON, 1973, modificado por Angy Domínguez). 
Clio Arqueológica 2020, V35N2, p.29-77, DOMINGUEZ DOI: 10.20891/clio.V35V2p29-77

\begin{tabular}{|c|c|c|c|c|c|c|c|c|}
\hline No. & $\begin{array}{l}\text { No. } \\
\text { Bolsa }\end{array}$ & Sector & Grupo & Usos & Forma/Tipo & $\begin{array}{l}\text { Categoría/ } \\
\text { Función }\end{array}$ & Imagen & Materia Prima \\
\hline 1 & 1889 & TL6 & Terminado & Ornamental & $\begin{array}{c}\text { No } \\
\text { Determinada }\end{array}$ & Diente & & Jadeita \\
\hline 2 & 1762 & TL6 & Terminado & Ornamental & $\begin{array}{c}\text { No } \\
\text { Determinada }\end{array}$ & Pectoral & & Jadeíta \\
\hline 3 & 1078 & TL6 & Terminado & Votivo & Antropomorfa & Figurilla & & Serpentina \\
\hline 4 & N5W1-2 & TL9 & Terminado & Votivo & Antropomorfa & Figurilla & & Serpentina \\
\hline 5 & N5W1-2 & TL9 & Terminado & Votivo & Antropomorfa & Figurilla & & Serpentina \\
\hline 6 & 1974 & TL6 & Terminado & Utilitario & Discoidal & Apliación & & Cuarzo/Jadeíta* \\
\hline 7 & 1025 & TL6 & Terminado & Ornamental & Circular & Cuenta & & Jadeíta** \\
\hline 8 & 449 & TL1 & Terminado & Ornamental & Esférica & Cuenta & & $\begin{array}{c}\text { Jadeíta } \\
\text { mezclada** }\end{array}$ \\
\hline 9 & 113 & TL1 & Terminado & Ornamental & Esférica & Cuenta & & Serpentina \\
\hline
\end{tabular}

Tabla 1. Piezas que conforman el cuerpo de estudio (Elaborado por Angy Domínguez). 
Clio Arqueológica 2020, V35N2, p.29-77, DOMINGUEZ DOI: 10.20891/clio.V35V2p29-77

\begin{tabular}{|c|c|c|c|c|c|c|c|c|}
\hline No. & $\begin{array}{l}\text { No. } \\
\text { Bolsa }\end{array}$ & Sector & Grupo & Usos & Forma/Tipo & $\begin{array}{l}\text { Categoria/ } \\
\text { Función }\end{array}$ & Imagen & Materia Prima \\
\hline 10 & $\begin{array}{l}\text { N5W1-2 } \\
\text { (TL9) }\end{array}$ & TL9 & Terminado & Ornamental & Esférica & Cuenta & & Jadeíta \\
\hline 11 & 2044 & TL6 & Terminado & Ornamental & Discoidal & Cuenta & & Cuarzo \\
\hline 12 & 1425 & TL11 & Terminado & Ornamental & Discoidal & Cuenta & & Serpentina \\
\hline 13 & $\begin{array}{l}\text { N5W1-2 } \\
\text { (TL9) }\end{array}$ & TL9 & Terminado & Ornamental & Esférica & Cuenta & & Jadeíta \\
\hline 14 & 1680 & TL6 & Terminado & Ornamental & Esférica & Cuenta & & $\begin{array}{c}\text { Cuarzo/Calcedon } \\
\text { ia }\end{array}$ \\
\hline 15 & 933 & TL6 & Terminado & Ornamental & Esférica & Cuenta & & Cuarzo \\
\hline 16 & 1991 & TL6 & Terminado & Ornamental & Esférica & Cuenta & & Cuarzo mezclado \\
\hline 17 & 1707 & TL6 & Terminado & Votivo & Esférica & Esfera & & Travertino \\
\hline 18 & 100 & TL1 & Terminado & Votivo & Esférica & Esfera & & Travertino \\
\hline
\end{tabular}

Tabla 1. Piezas que conforman el cuerpo de estudio (Elaborado por Angy Domínguez). Continuación. 


\section{Clio Arqueológica 2020, V35N2, p.29-77, DOMINGUEZ DOI: 10.20891/clio.V35V2p29-77}

\begin{tabular}{|c|c|c|c|c|c|c|c|c|}
\hline No. & $\begin{array}{l}\text { No. } \\
\text { Bolsa }\end{array}$ & Sector & Grupo & Usos & Forma/Tipo & $\begin{array}{l}\text { Categoría/ } \\
\text { Función }\end{array}$ & Imagen & Materia Prima \\
\hline 19 & 416 & TL7 & Terminado & Votivo & Esférica & Esfera & & Serpentina \\
\hline 20 & 527 & TL11 & Terminado & Votivo & Esférica & Esfera & & Cuarzo \\
\hline 21 & $\begin{array}{c}\text { N17W8- } \\
9\end{array}$ & TL1 & Terminado & Votivo & Trapezoidal & $\begin{array}{c}\text { Placa } \\
\text { Trapezoidal }\end{array}$ & & Serpentina \\
\hline 22 & 542 & TL11 & Terminado & Utilitario & $\begin{array}{c}\text { No } \\
\text { Determinada }\end{array}$ & Pulidor & & Serpentina \\
\hline 23 & 1243 & TL11 & En Proceso & $\mathrm{N} / \mathrm{T}$ & $\begin{array}{c}\text { No } \\
\text { Determinada }\end{array}$ & $\begin{array}{c}\text { Pieza } \\
\text { c/trabajo }\end{array}$ & & Jadeíta \\
\hline 24 & 2256 & TL6 & En Proceso & $N / T$ & $\begin{array}{c}\text { No } \\
\text { Determinada }\end{array}$ & $\begin{array}{c}\text { Pieza } \\
\text { c/trabajo }\end{array}$ & & Jadeíta \\
\hline 25 & 1822 & TL6 & En Proceso & $\mathrm{N} / \mathrm{T}$ & $\begin{array}{c}\text { No } \\
\text { Determinada }\end{array}$ & $\begin{array}{c}\text { Pieza } \\
\text { c/trabajo }\end{array}$ & & Serpentina \\
\hline 26 & 795 & TL7 & $\begin{array}{l}\text { Materia } \\
\text { Prima }\end{array}$ & $\mathrm{N} / \mathrm{T}$ & $\begin{array}{c}\text { No } \\
\text { Determinada }\end{array}$ & $\begin{array}{c}\text { Materia } \\
\text { Prima }\end{array}$ & & Serpentina \\
\hline
\end{tabular}

Tabla 1. Piezas que conforman el cuerpo de estudio (Elaborado por Angy Domínguez). Continuación. 
A continuación, se explican las diferentes técnicas empleadas en la metodología de esta investigación para la identificación de las materias primas que conforman el cuerpo de la colección y las tradiciones tecnológicas de las piezas. Los análisis llevados a cabo fueron: Fluorescencia de Luz UV, Espectroscopía por Dispersión de Energía de Rayos X (EDS), Espectroscopía Micro Raman, y Micrografías de Huellas de Manufactura observadas en el Microscopio Electrónico de Barrido. También se empleó la Arqueología Experimental para recrear las tecnologías y realizar las comparaciones pertinentes.

\section{FLUORESCENCIA DE LUZ ULTRAVIOLETA (UV)}

La fluorescencia de luz ultravioleta es una técnica no destructiva y asequible que permite una aproximación preliminar sobre la variabilidad, homogeneidad y heterogeneidad en la composición de un objeto y consiste en:

"la absorción selectiva de fotones o radiación electromagnética que ocurre al irradiar un material con una fuente de luz UV en un cuarto oscuro. Para aplicaciones científicas, estas lámparas deben tener al menos dos frecuencias de onda, a 365nm u onda larga y a $254 \mathrm{~nm} u$ onda corta. Los resultados de esta técnica se registran con cámara fotográfica o digital con filtro UV' (MELGAR Y SOLÍS, 2008: 4).

Esta técnica nos permite observar las impurezas, la homogeneidad y la heterogeneidad de los objetos y materias primas. También se pueden registrar preliminarmente otros materiales como jadeíta, serpentina, serpentinita, azabache, 
travertino, filita, lutita, esquisto, malaquita, crisocola, cuprita y calcopirita, entre otros (MELGAR Y SOLÍS, 2008: 4).

Cabe señalar que esta técnica debe realizarse en conjunto con otras complementarias como espectroscopia Micro Raman y Difracción de Rayos X para corroborar la identificación del material y la fuente de las materias primas.

Para la toma de fotografías se empleó una lámpara mineralógica portátil marca UVP modelo UVGL-58 con bulbo de vapor de mercurio, a la que es posible controlar la energía emitida por medio de un interruptor que permite cambiar las longitudes de onda corta (254 nm) a onda larga (365 nm). Asimismo, para la captura de imágenes se empleó una cámara Canon modelo Power Shot A640 con filtro UV integrado.

En la Figura 3 se presenta la fotografía de Luz UV de dos fragmentos de travertino, uno procede de un yacimiento de la mixteca-poblana (superior izquierda) y el otro de los depósitos de Tecali, Puebla (Superior derecha) (MELGAR, 2019: comunicación personal). En las imágenes $\mathrm{B}$ y $\mathrm{C}$ que corresponden a la onda corta y larga respectivamente se aprecia una reverberación diferente de los objetos en ambos casos debido a que, a pesar de ser el mismo material, proceden de distintos yacimientos.

Cabe resaltar que estos son muestras geológicas de referencia a partir de las cuales se comparan las piezas de travertino de la presente investigación.

Además, se presentan las fotografías de luz normal (izquierda), luz ultravioleta en onda corta $(254 \mathrm{~nm})$ y onda larga $(365 \mathrm{~nm})$ de objetos de cuarzo (3a), travertino 
(3b), calcedonia (3c) y jadeíta (3d). Como se observa, a la luz de onda corta se notan muchas diferencias en cuanto a la iridiscencia de las piezas, de las cuales, las más similares entre sí son la esfera de travertino (3b) y la cuenta de calcedonia (3c). Lo anterior se debe a que la composición de ambas consta básicamente de carbonatos de calcio; mientras que la esfera de cuarzo (3a) tiene muy poca iridiscencia; asimismo la cuenta de jadeíta tiene una reverberación ${ }^{3}$ diferente a las demás piezas. En la fotografía de luz UV de onda larga se aprecia una ligera similitud entre la cuenta (3c) y la esfera (3b). La esfera (3a) es la más opaca de las tres piezas y, finalmente, la cuenta (3d) en este caso presenta una iridiscencia azulada lo que es característica de algunas jadeítas.

Aunado a lo anterior, cabe agregar que, en término generales, los artefactos presentados en el presente artículo como ejemplos ${ }^{4}$ son bastante homogéneos a comparación de las intrusiones que presenta la muestra de travertino de la mixtecapoblana las cuales brillan de manera más notoria en la fotografía de onda larga.

\footnotetext{
${ }^{3}$ Reverberación se refiere a la reflexión difusa de la luz o del calor (definición de la Real Academia Española). Esto se refiere a como la luz se refleja sobre la superficie de un objeto.

${ }^{4}$ No se muestran todos los objetos debido a cuestiones de espacio.
} 


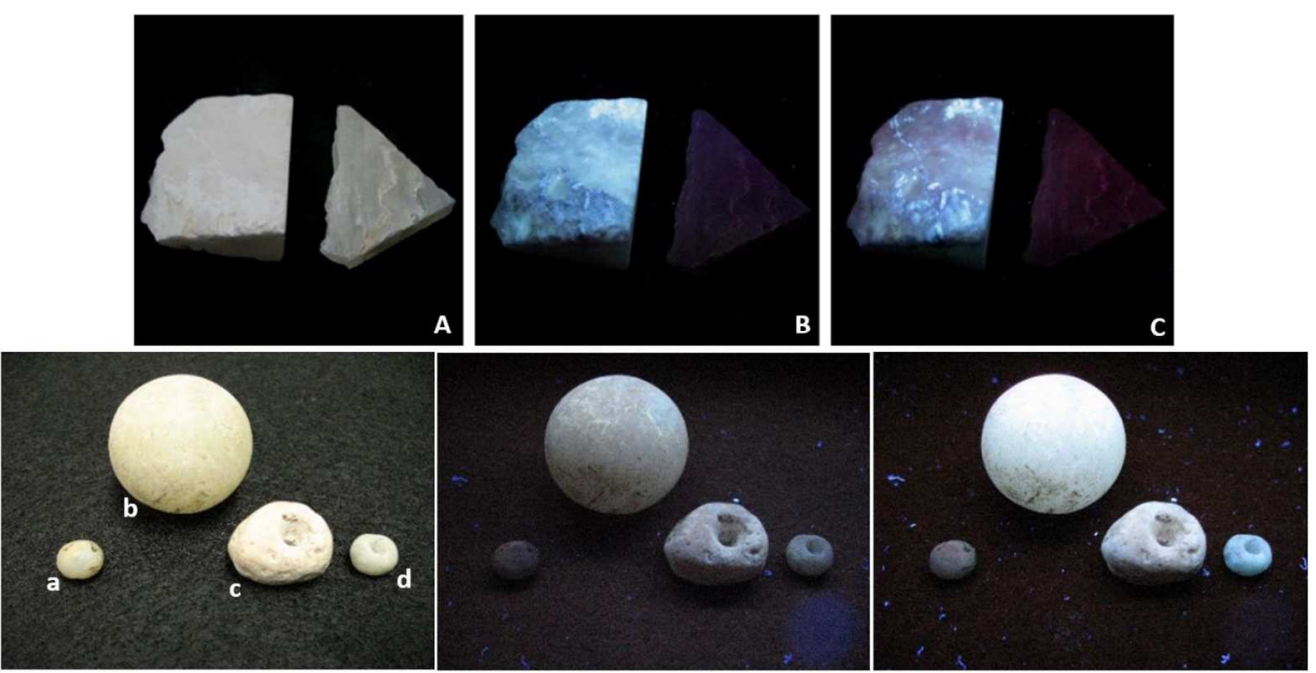

Figura 3. Fotografías de luz UV de muestras geológicas de referencia de travertino (A, B y C) y piezas arqueológicas de cuarzo (a), travertino (b), calcedonia (c) y jadeíta (d). De izquierda a derecha: luz normal, onda corta y onda larga (Fotografías: Emiliano Melgar y Angy Domínguez).

En el próximo ejemplo se observan dos piezas de jadeíta (Figura 4) que presentan similitudes en onda corta, empero, en onda larga se aprecian más claramente las intrusiones $\mathrm{y}$, en el caso del diente (4a), se distinguen visiblemente las vetas de jadeíta (color claro que coincide con las de la Imagen $3 \mathrm{~d}$ en onda larga) y serpentina (veta obscura que en pequeñas zonas recuerda a la iridiscencia de la muestra geológica), de ahí que presente diferentes tonos verdes. A pesar de que ambas son jadeítas se observa en el pectoral (4b) una iridiscencia más obscura, lo que indica que, como ya se ha mencionado antes, contiene otros compuestos y/o un depósito 
diferente, aunque es importante mencionar que el intemperismo que sufren los artefactos también modifican la forma en que responden a la luz ultravioleta.
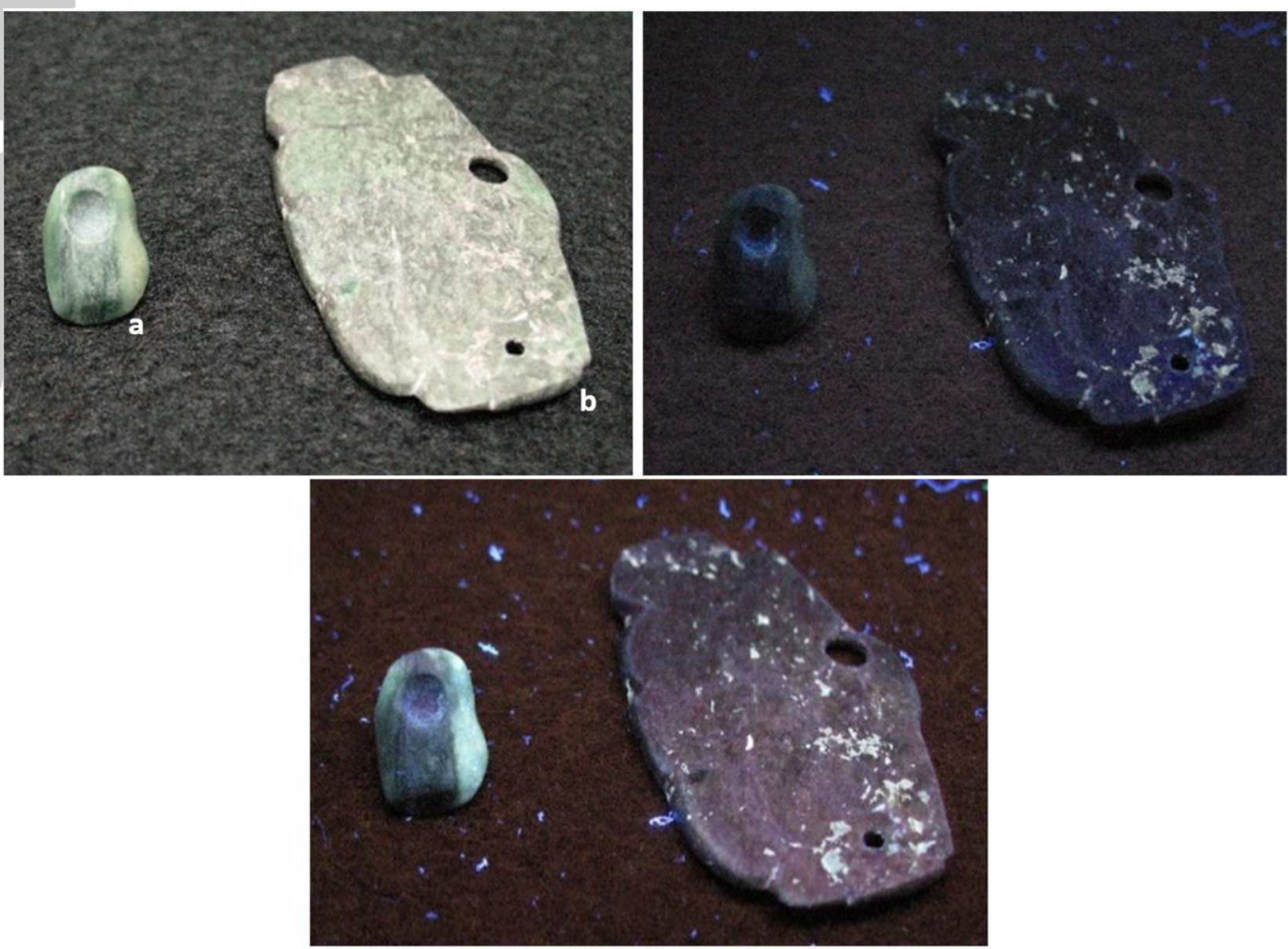

Figura 4. Fotografías de luz UV de objetos de jadeíta. De izquierda a derecha: luz normal, onda corta y onda larga (Fotografías: Emiliano Melgar y Angy Domínguez). 


\section{ESPECTROSCOPÍA POR DISPERSIÓN DE ENERGÍA DE RAYOS X (EDS)}

El Microscopio Electrónico de Barrido (MEB) cuenta con un Detector de Energía Dispersiva (EDS por siglas en inglés) que permite hacer una lectura de la distribución de los elementos químicos de un objeto en partes por millón (PÉREZ, 2016: 142), cualquiera que sea su naturaleza.

Al barrer la superficie con el haz de electrones, el Microscopio Electrónico de Barrido ocasiona que los átomos pierdan electrones generando Rayos X, los cuales, son captados por el Detector de Energía Dispersiva proporcionando información característica de cada elemento químico como su peso atómico (Ing. Mario Monroy, 2018: comunicación personal), de este modo, es posible conocer la composición elemental de cada objeto lapidario y determinar tentativamente el tipo de materia prima, por ejemplo, el tipo de piedra verde, ya sea jadeíta, un alumino-silicato rico en sodio $\mathrm{Na}(\mathrm{Al}, \mathrm{Fe}) \mathrm{Si2O} 6)^{5}$ (WALKER, 1991: 23; CASTAÑóN, 2014: 132, 144) (Figura 5); una serpentina, alumino-silicato rico en magnesio (Mg3Si205(OH)4) (GONZÁLEZ, 2001: 4) (Figura 6) o cualquier otra roca de tonalidades verdes.

\footnotetext{
${ }^{5} \mathrm{La}$ fórmula $\left.\mathrm{Na}(\mathrm{Al}, \mathrm{Fe}) \mathrm{Si} 2 \mathrm{o6}\right)$ es de la jadeíta como roca, si se la encuentra como mineral sería la siguiente: NaAlSi2O6 (CASTAÑÓN, 2014: 132, 144).
} 

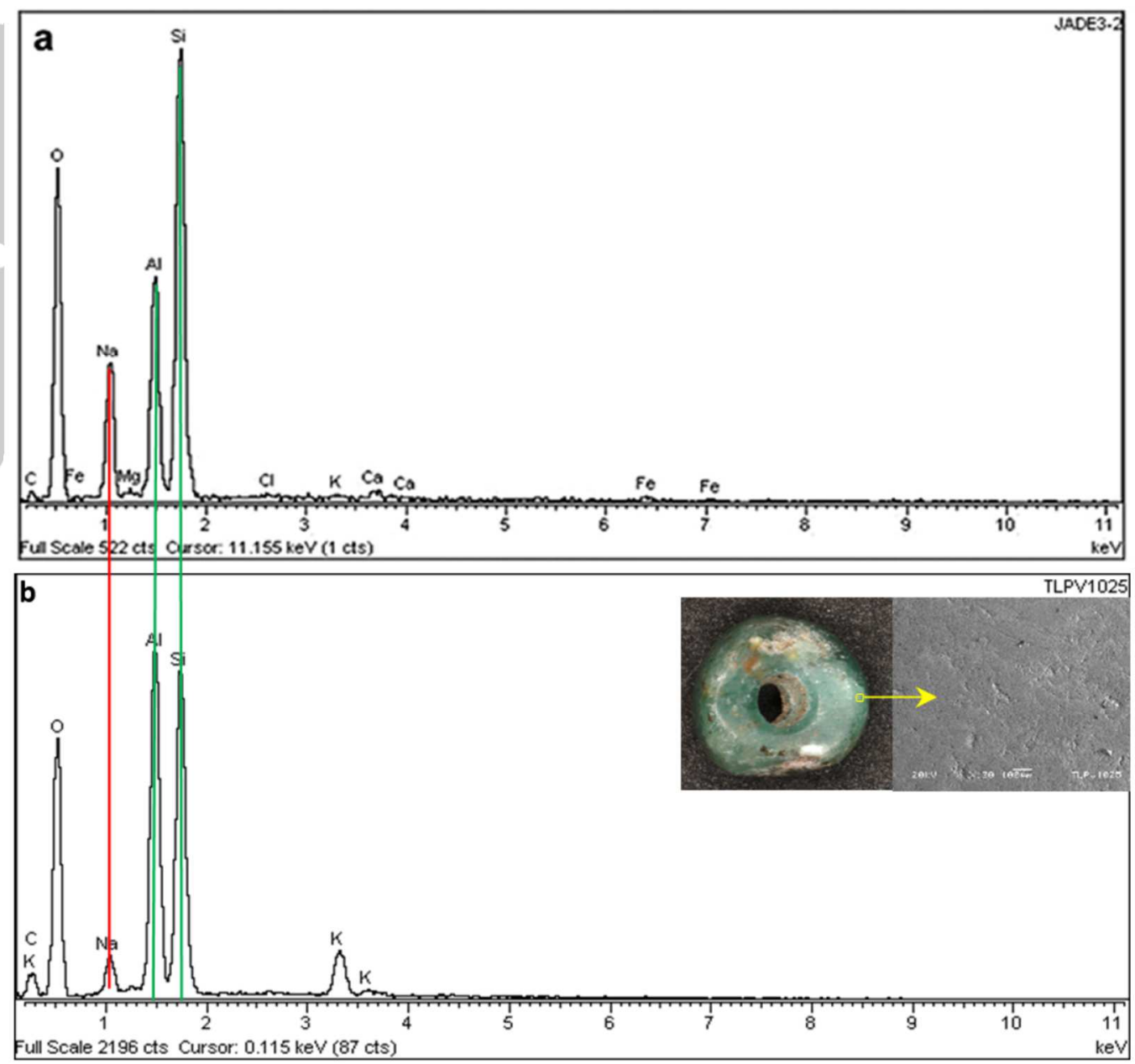

Figura 5. Espectro de una jadeíta (NaAlSi2O6) de referencia del Valle del Motagua, Guatemala (a) y pieza arqueológica (Espectro de referencia proporcionado por Emiliano Melgar).

El Detector de Energía Dispersiva proporciona la composición química-elemental de las piezas y una imagen en escala de grises que muestra la topografía de la pieza 
en la zona analizada donde se extrajo el espectro; estas imágenes se tomaron en un aumento de 100x para poder apreciar toda el área.

El MEB empleado fue el modelo Jeol JSM-6460LV ubicado en el Laboratorio de Microscopía Electrónica de la Subdirección de Laboratorios y Apoyo Académico del Instituto Nacional de Antropología e Historia (INAH). Este estudio se realizó a todas las piezas y se concluyó la presencia de jadeíta (NaAlSi2O6), lo que se corroboró haciendo una comparación con una muestra geológica de referencia de los yacimientos del Valle del Motagua en Guatemala (Figura 5). En ambos espectros se aprecian claramente los tres picos característicos de la jadeíta que son el sodio (Na) como principal elemento, el aluminio ( $\mathrm{Al}$ ) y el silicio $(\mathrm{Si})$.

Tambièn se identificó la presencia de serpentina $(\mathrm{Mg} 3 \mathrm{Si} 205(\mathrm{OH}) 4)$ (Figura 6), compuesta por aluminio $(\mathrm{Al})$, silicio $(\mathrm{Si})$ y magnesio $(\mathrm{Mg})$, siendo este último el principal elemento que la diferencia de la jadeíta. De la misma forma, se recurrió a la comparación con una muestra de referencia que procede de las minas de Tehuitzingo, Puebla y los tres elementos mencionados están presentes como se señala en la Figura 6. Los últimos materiales identificados fueron carbonatos de calcio $(\mathrm{CaCO} 3)$ entre los que se incluye travertino, y, los dióxidos de sílice formados por los elementos silicio y el oxígeno ( $\mathrm{SiO} 2)$ principalmente y engloban los cuarzos y pedernales (Figuras 7 y 8 respectivamente) (CASTAÑ́n, 2014: 128, 132, 144; MELGAR, 2018: comunicación personal). 

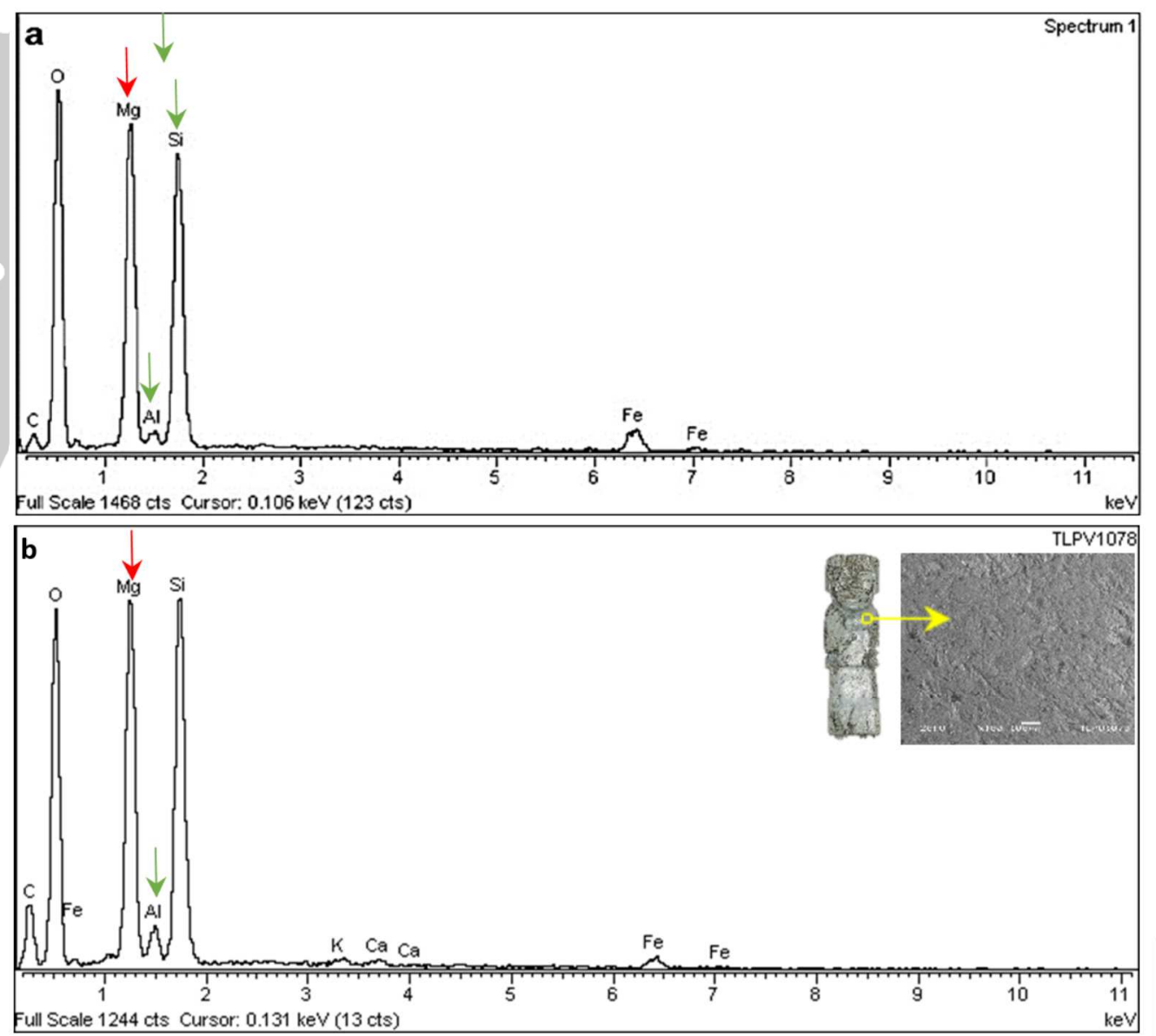

Figura 6. Espectro de una serpentina de referencia de Tehuitzingo, Puebla (a) y pieza arqueológica (b) (Espectro de referencia proporcionado por Emiliano Melgar). 

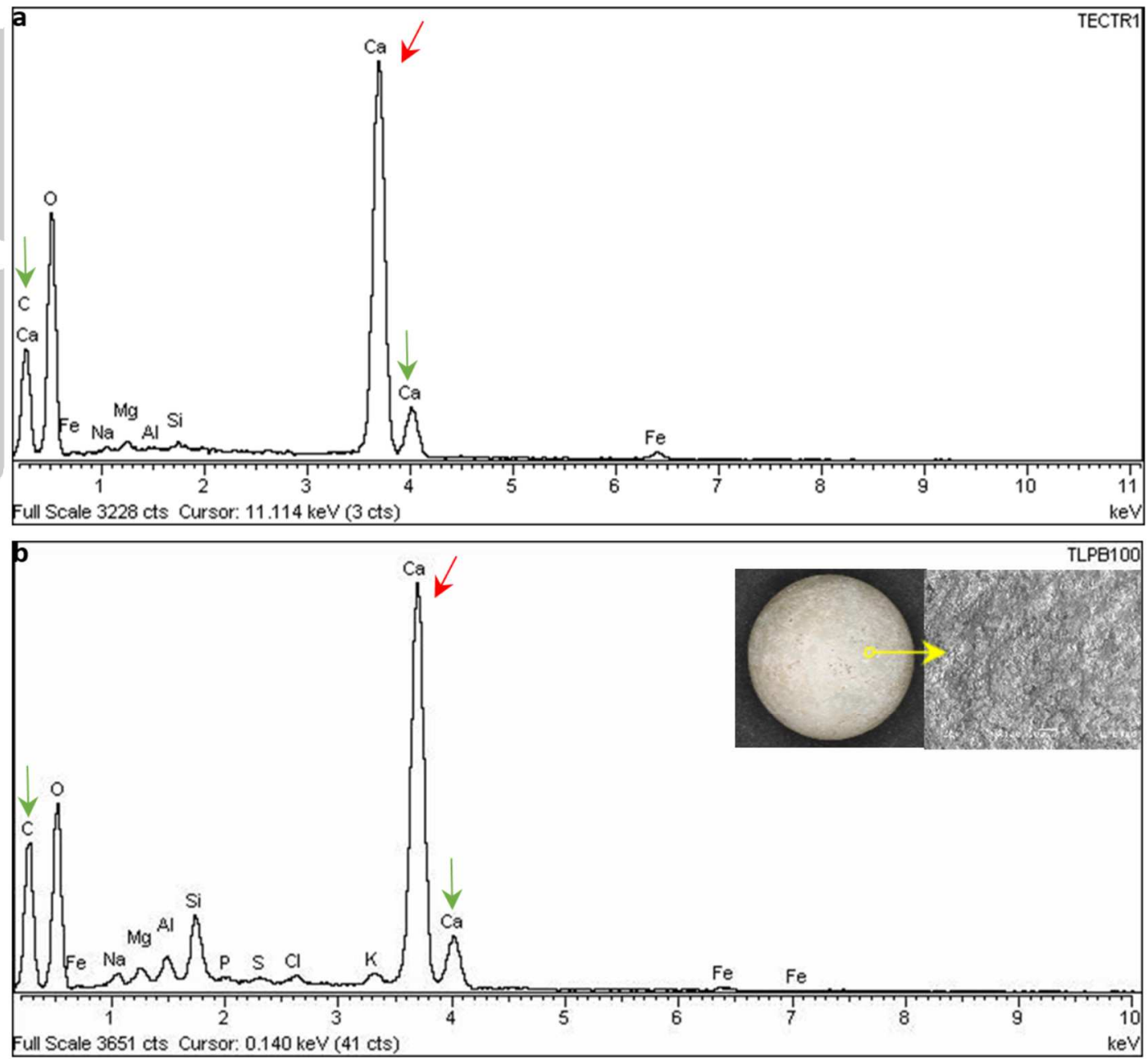

Figura 7. Carbonatos de Calcio o travertinos: muestra geológica (a) y pieza arqueológica (b) (Espectro de referencia proporcionado por Emiliano Melgar). 


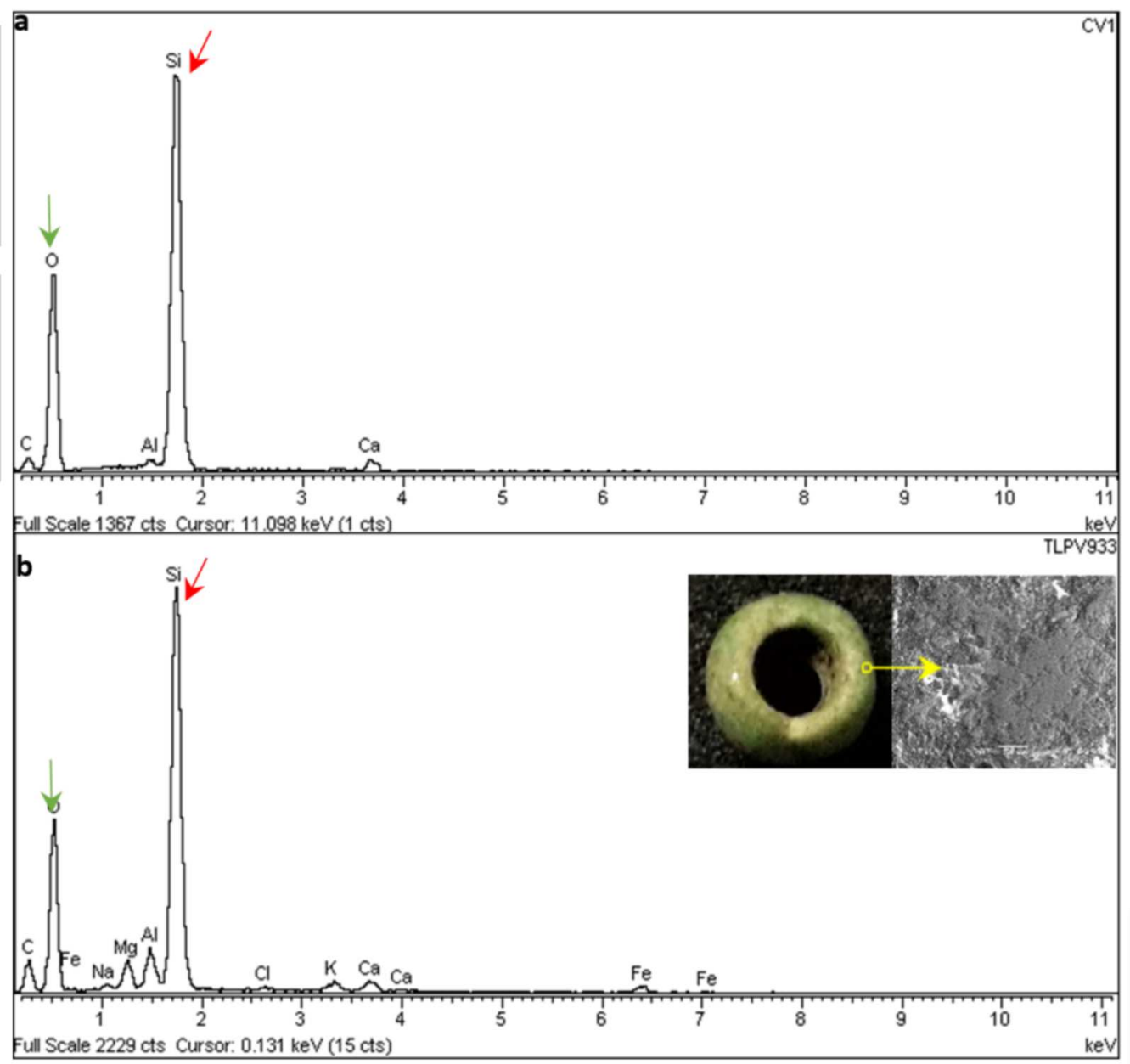

Figura 8. Comparación de los espectros de dióxidos de sílice de la pieza de referencia (a) y la pieza arqueológica (b) (Espectro de referencia proporcionado por Emiliano Melgar). 


\section{ESPECTROSCOPÍA MICRO-RAMAN}

El Micro-Raman es un instrumento de alta sensibilidad que proporciona los compuestos de las muestras y los enlaces moleculares de los elementos de las piezas que, con la comparación adecuada con muestras de referencia, permite identificar el yacimiento de donde provienen las materias primas.

La técnica consiste en someter la muestra a un haz de luz monocromático. La mayor parte del haz se dispersa elásticamente al incidir en la superficie de la muestra, esto se denomina radiación Rayleigh, mientras que la luz (alrededor de una millonésima parte) que se dispersa inelásticamente, es lo que se conoce como dispersión Raman. A partir de esta radiación se obtiene la información vibracional de cada una de las moléculas de los artefactos analizados. Esta vibración captada por el Micro-Raman es distintiva de cada enlace molecular, por esa razón, es posible identificar uno de otro (GÁZQUEZ, et al., 2014: 298; UNIVERSIDAD COMPLUTENSE DE MADRID, n. d.).

El equipo empleado fue el Micro Raman Modelo Thermo Scientific DXR con un láser verde de $532 \mathrm{~nm}$, un objetivo de 50x5, un intervalo espectral de 0 a $3500 \mathrm{~cm}$ 1 , un tiempo de adquisición de 10 repeticiones de 10 segundos generalmente y 50 $\mu \mathrm{m}$ de apertura. Este equipo se encuentra en el Laboratorio de Materiales Avanzados del Instituto de Física de la Universidad Nacional Autónoma de México (UNAM) y fue manejado por la Mtra. Cristina Zorrilla Cangas. Los espectros resultantes fueron procesados y analizados en el programa OMNIC®. 
Respecto a su composición molecular, la jadeíta tiene tres grandes picos principales y característicos en los rangos de $368-375 \mathrm{~cm}^{-1}$ que corresponden a los enlaces de Al-O; 684-696 cm-1 correspondientes a los enlaces de flexión de Si-O y 1028-1036 $\mathrm{cm}^{-1}$ pertenecientes los enlaces Si-O de estiramiento. Por su parte, las serpentinas (Mg3Si2O5(OH)4) poseen tres picos específicos ubicados entre 220-235, 370-385 y $680-695 \mathrm{~cm}^{-1}$. Los cuarzos (dióxidos de sílice [SiO2]) cuentan con el pico principal de las rocas silíceas entre 460 y $475 \mathrm{~cm}^{-1}$ más otros dos más pequeños entre $120-130 \mathrm{~cm}-1$ y $200-210 \mathrm{~cm}^{-1}$. Finalmente, los travertinos, que son carbonatos de calcio (CaCO3) presentan un pico principal entre el 1080 y $1090 \mathrm{~cm}^{-1}$ y otros dos más chicos en 712 y $280 \mathrm{~cm}^{-1}$ (LALLA, et. al., 2015; DELGADO, 2015: 87; MELGAR Y SOLÍS, 2018: 636-640; MONTERROSA, 2018: 55).

En virtud de lo anterior, se compararon los espectros Raman de la presente colección con los de referencia (muestras geológicas). En la Figura 9 superior se presentan la muestra de referencia de una jadeíta procedente del Motagua, donde se aprecian los tres principales picos de la jadeíta y otros más pequeños. En la Figura 9 inferior se muestran las piezas arqueológicas que coinciden con la composición molecular de la jadeíta en distintas intensidades, reflejadas en la altura de los picos.

El siguiente conjunto de Espectros (Figura 10) es el de serpentinas de referencia procedentes de Tehuitzingo, Puebla (Figura 10a); del Motagua, (Figura 10b) y de Taxco, Guerrero (Figura 10c), se puede observar que los picos coinciden; no obstante, la intensidad o altura de los mismos varía notablemente lo que indica la 


\section{Clio Arqueológica 2020, V35N2, p.29-77, DOMINGUEZ DOI: 10.20891/clio.V35V2p29-77}

procedencia de lugares diferentes. En lo referente a las piezas arqueológicas (Figura 11) es posible observar el patrón característico de las serpentinas de Tehuitzingo, Puebla, en los distintos picos de todos los espectros a pesar del hecho de que el fragmento de materia prima TLPV1822 (color verde en espectros apilados) tiene mezclas de otros componentes que hacen que en su composición molecular aparezca un pico extra cerca de los $600 \mathrm{~cm}^{-1}$. Lo anterior sugiere que todos los objetos de serpentina proceden de los yacimientos de Tehuitzingo, Puebla.

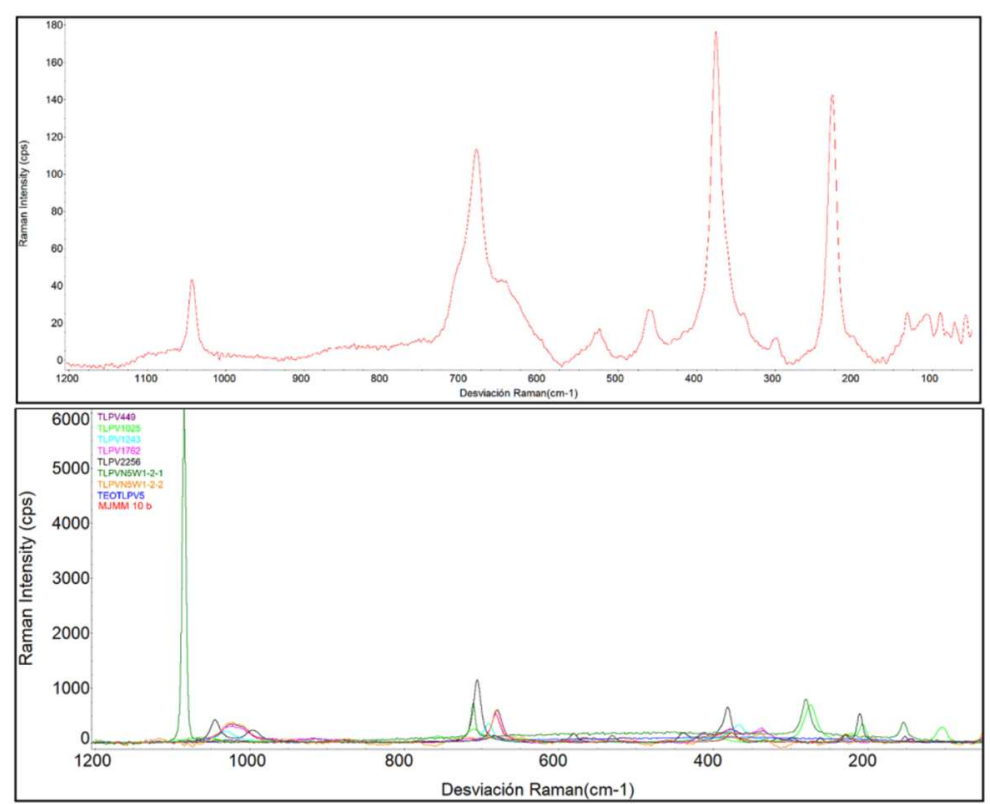

Figura 9. Espectro de una jadeíta geológica (espectro superior) de referencia del Valle del Motagua, Guatemala y Espectros Raman de las piezas arqueológicas de jadeíta empalmados con la muestra geológica (Espectro inferior). 

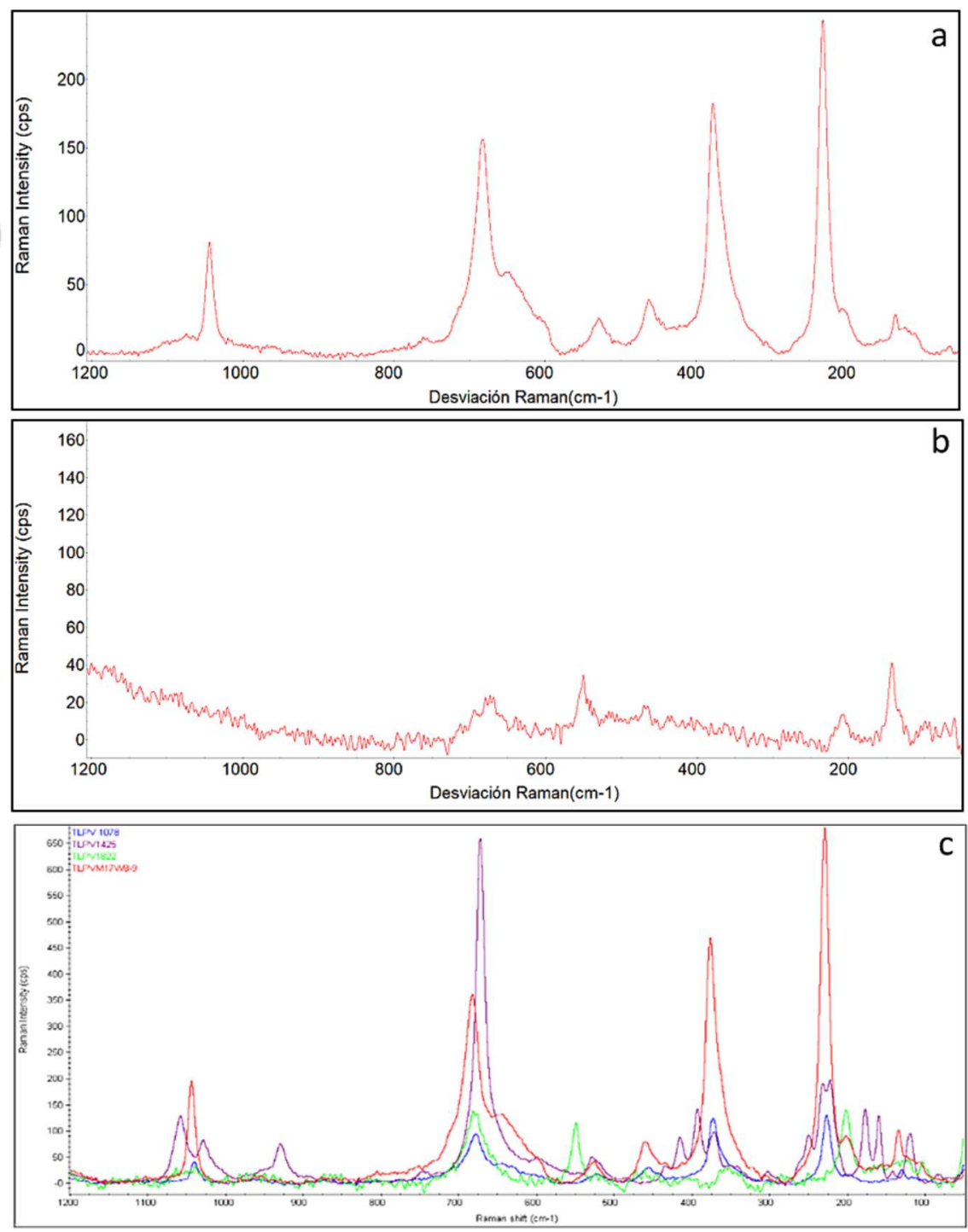

Figura 10. Serpentinas de Tehuitzingo, Puebla (a) y de Taxco, Guerrero (b). Espectros empalmados de piezas arqueológicas de serpentina de Tlailotlacan (c). 
De los once objetos de cuarzo identificadas, se registraron dos grupos: 1) Cuarzos procedentes del Estado de Guerrero cuya muestra geológica se muestra en la Figura 11a comparado con piezas de Teopancazco; mientras que en la Figura 11b se presentan las siete piezas de Tlailotlacan que coinciden con la muestra geológica y los de Teopancazco. 2) Cuarzo con doble pico en torno a los $500 \mathrm{~cm}^{-1}$ (Figura 11c), que pueden equipararse con la muestra geológica de la Figura 11d donde se compara con otra serie de objetos arqueológicos pertenecientes a Xalla, Teotihuacán. Lo anterior confirma que se trata de cuarzos provenientes de Chiapas; no obstante, Emiliano Melgar (2019: comunicación persona) sugiere que pueden tratarse de un componente de una roca llamada granodiorita que también posee el doble pico como los anteriores, además de elementos tales como el aluminio, sodio, hierro y silicio.

Esta técnica sustentó lo que se concluyó con el Detector de Energía Dispersiva y también permitió la identificación de algunas rocas cuyo espectro de EDS no fue tan claro. Lo anterior se refiere a que se corroboró la presencia de jadeíta, serpentina, cuarzo y travertino. 


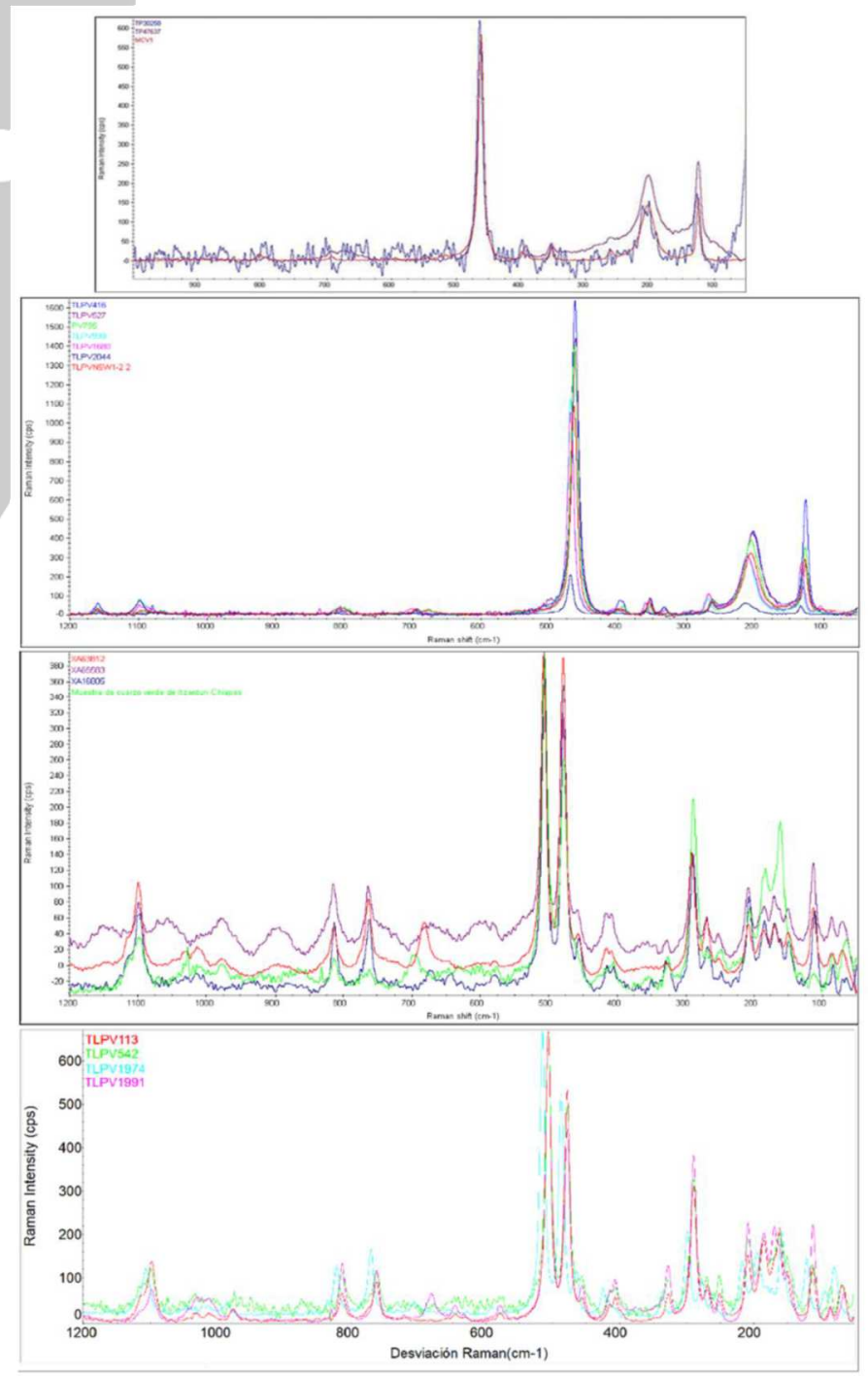

Figura 11. Muestra geológica de cuarzo precedente de Guerrero y piezas de Teopancazco (a). Piezas de Tlailotlacan que coinciden con la muestra geológica y las piezas de Teopancazco (b). Muestra de referencia de Chiapas y piezas de Xalla, Teotihuacán (c). Piezas de Tlailotlacan que coinciden con la muestra de Chiapas y artefactos de Xalla (d). 


\section{ARQUEOLOGÍA EXPERIMENTAL Y HUELLAS DE MANUFACTURA}

Para poder identificar las tradiciones tecnológicas presentes en Tlailotlacan se partió de una revisión bibliográfica de lo que se ha encontrado y estudiado anteriormente por otros autores para Teotihuacán y sus vecindarios. De acuerdo con las fuentes consultadas (GAZZOLA, 2005; 2007; 2009; MELGAR, 2006; 2017: 121-123; MELGAR, et. al., 2012a: 250-257; 2014: 49-53; LÓPEZ, 2011: 124-133, 173-174; TURNER, 1992: 95-103;), se hizo la reconstrucción de las cadenas operatorias de las tecnologías teotihuacana, ${ }^{6}$ zapoteca (de Monte Albán) y maya (Tierras Bajas Mayas). Para la primera se examinaron textos que abordan el análisis de objetos de pizarra, travertino, serpentina, pirita y piedras verdes en general concluyendo que es la misma cadena operativa y consiste en lo siguiente:

1) Desgaste: los desgastes y los acabados se elaboraron con lajas de andesita. Las piezas desgastadas con este material presentan superficies aplanadas y algo rugosas con rayones que consisten en bandas paralelas rectas y/o entrecruzadas de $66 \mu \mathrm{m}$ de espesor visibles desde 100x (Figura 12a y b). ${ }^{7}$ Las huellas anteriores se diferencian de las del basalto cuyas bandas miden $100 \mu \mathrm{m}$ y en el caso de la riolita $33 \mu \mathrm{m}$.

2) Pulido y bruñido: las superficies de los artefactos fueron pulidas empleando nódulos de pedernal y posteriormente bruñidas con piel. Las huellas características son zonas aplanadas cruzadas por sucesiones

\footnotetext{
${ }^{6}$ Las investigaciones citadas abarcan objetos procedentes principalmente de Teopancazco, La Ventilla, la Pirámide de la Luna y otros sitios mencionados dentro de los mismos textos.

${ }^{7}$ Las imágenes son meramente ilustrativas y fueron tomadas de Melgar, et. al., 2012: 250-257 para ilustrar los rasgos descritos presentes en la superficie de los artefactos que denotan las técnicas referidas.
} 
ininterrumpidas de bandas rectas y paralelas de 2 a $5 \mu \mathrm{m}$ de ancho, visibles a 1000x (Figura 12c y d).

3) Cortes: los bordes resultantes de la acción de cortar con lascas de pedernal muestran rayones rectos bien definidos, es decir, una sucesión de bandas rectas-paralelas de 2-5 $\mu \mathrm{m}$ visibles a 1000x (Figura 12e y f).

4) Incisiones (sobre todo en figurillas antropomorfas): se hacían con lascas de pedernal cuyas huellas son rayones rectos bien definidos o bandas rectas-paralelas de 2-5 $\mu \mathrm{m}$ de ancho visibles a 1000x (Figura 12g y h).

La tecnología zapoteca, por su parte, también tiene una marcada estandarización en las herramientas y procesos identificados, ya sea que éstos se empleen en materiales malacológicos o en lapidaria. Los estudios sobre tecnología zapoteca son escasos hasta la fecha. El Dr. Emiliano Melgar y colegas (2010: 21) han arrojado luz sobre tradición tecnológica zapoteca de Monte Albán durante el periodo Clásico. La cadena operativa se reconstruye de la siguiente manera (MELGAR, et al., 2010: 621):

1) Desgaste: el desgaste se realiza con basalto, cuyas huellas son superficies aplanadas con bandas cruzadas de $100 \mu \mathrm{m}$ visibles a $100 \mathrm{x}$ (Figura 13a y b).

2) Pulido y bruñido: estas modificaciones se realizan con arena como abrasivo y posteriormente se bruñe con piel. El resultado de esto son rayones finos de $1.3 \mu \mathrm{m}$ de ancho visibles a 1000x (Figura 13c y d).

3) Cortes: elaborados con pedernal, sus huellas son rayones paralelos, es decir, bandas que van 2 a $4-5 \mu \mathrm{m}$ de espesor visibles a 1000x (Figura 12e y f). También se registran cortes hechos con obsidiana que presentan líneas de 0.6 a $2 \mu \mathrm{m}$ (Figura 13e y f). 
4) Incisiones: se hacían con lascas de pedernal cuyas huellas son rayones rectos bien definidos o bandas rectas-paralelas de 2-5 $\mu \mathrm{m}$ de ancho visibles a 1000x (Figura 12g y h). También se identificaron incisiones con obsidiana cuyas huellas son líneas que van de 0.6 a $1.6 \mu \mathrm{m}$ de ancho (Figura 13g y h).

5) Perforaciones: estas se realizan con perforadores de pedernal, cuyas huellas son bandas de 2 a $4 \mu \mathrm{m}$ en círculos concéntricos en torno a la horadación, visibles a partir de 600x en adelante (Figura 12i y j). Las piezas destinadas al consumo de la élite se perforaban con obsidiana cuyas huellas son círculos concéntricos que van de 0.6 a $1.6 \mu \mathrm{m}$ de ancho.

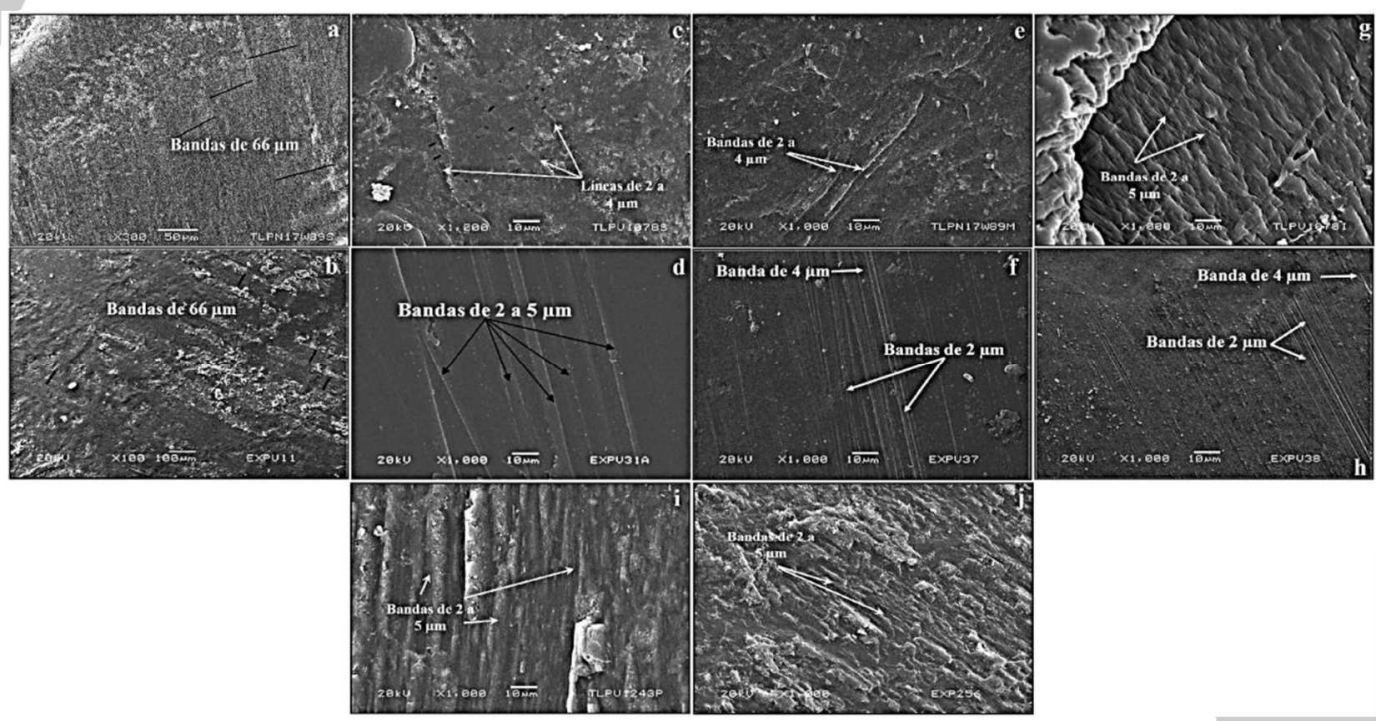

Figura 12. Desgaste con andesita de una placa trapezoidal de serpentina procedente de Tlailotlacan (a); desgaste experimental con andesita (b); acabado de superficie de una figurilla antropomorfa de Tlailotlacan con pedernal y piel (c); acabado de superficie experimental con pedernal y piel (d); corte de una placa trapezoidal de Tlailotlacan (e); corte experimental con pedernal (f); incisión de una figurilla antropomorfa de Tlailotlacan (g); incisión experimental con pedernal (h); perforación en pieza con trabajo de Tlailotlacan (i) y perforación experimental con pedernal (j). 


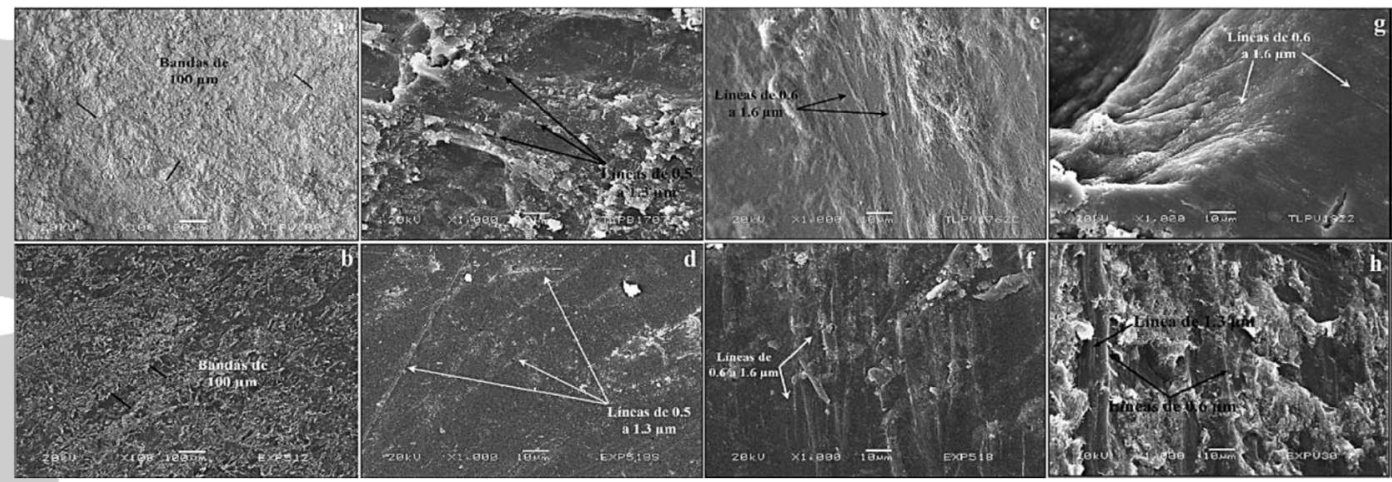

Figura 13. Desgaste con basalto de una esfera de travertino de Tlailotlacan (a); desgaste experimental con basalto (b); acabado de superficie de una esfera de travertino de Tlailotlacan (c); acabado de superficie experimental con arena, basalto y piel (d); corte de una placa incisa de Tlailotlacan (e); corte experimental con obsidiana (f); incisión de un fragmento trabajado de Tlailotlacan (g) e incisión experimental con obsidiana (h).

Finalmente, se reconstruye la cadena operativa de la tecnología lapidaria maya (MELGAR, 2017:121-123; MELGAR y ANDRIEU, 2016: 1067-1068; MELGAR y DOMÍNGUEZ, 2014: 207-209; MELGAR et al., 2014: 49-53; 2018: 172-188; MONTERROSA, 2018; MONTERROSA y MELGAR, 2017a: 219-220; 2017b: 907-908; MELGAR y SOLÍS, 2010: 387-390; 2016: 81-85; 2018) (Tabla 2):

1) Desgastes: esta modificación se realizaba con lajas de caliza, cuyas huellas son superficies aplanadas con una serie de bandas de $20 \mu \mathrm{m}$ visibles a 100x (Figura 14a y b).

2) Pulidos: los pulidos se elaboraban con nódulos de jadeíta, cuyas huellas son finas líneas de 1-2 $\mu \mathrm{m}$ visibles a 1000x y que cruzan las bandas del desgaste (Figura 14c y d). 
Cortes: estos se hacían con lascas de obsidiana y presentan finas líneas de 0.7-1.6 $\mu \mathrm{m}$ de ancho visibles a 1000x (Figura 13e y f).

3) Perforaciones y calados: realizados con polvo de pedernal como abrasivo y carrizo, lo que da como consecuencia bandas irregulares de 1 $\mu \mathrm{m}$ de ancho visibles a 1000x (Figura 14e y f), las cuales son considerablemente más pequeñas que las huellas dejadas por una herramienta lítica como el pedernal, incluso su tamaño es aún menor que las que deja la arena empleada como abrasivo debido a la finura del grano del polvo de pedernal. Algunos objetos llegan a presentar estas modificaciones elaboradas con buriles de pedernal que muestran tiras de 2-4 $\mu \mathrm{m}$; aunque lo más común es realizarlas con obsidiana.

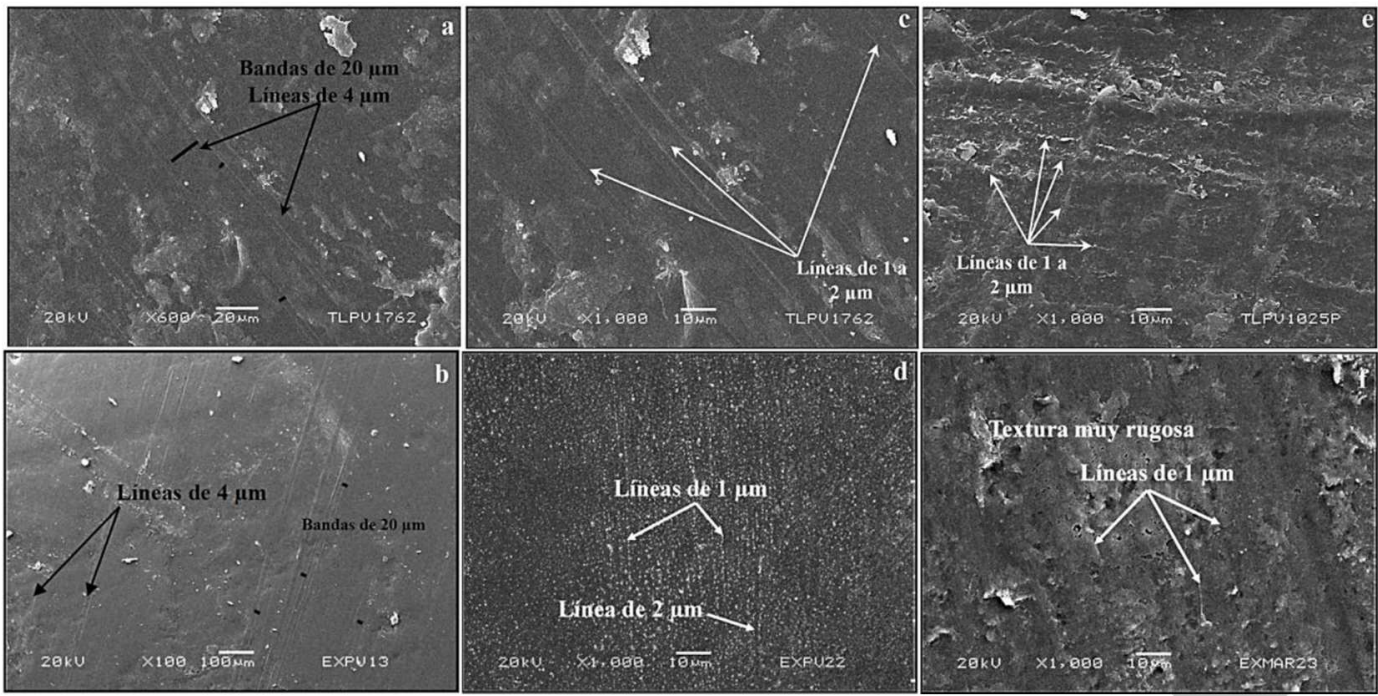

Figura 14. Desgaste de superficie de una placa incisa de Tlailotlacan (a); desgaste experimental con caliza (b); acabado de superficie de placa incisa de Tlailotlacan (c); acabado de superficie con nódulo de jadeíta y piel (d); perforación de una cuenta de jadeíta de Tlailotlacan (e); perforación experimental con carrizo y polvo de pedernal (f). 
Para poder obtener información sobre las herramientas, técnicas y formas de producción empleadas en los objetos lapidarios de Tlailotlacan, así como un punto de comparación, se empleó la Arqueología Experimental que "ofrece instrumentos que permiten esclarecer estos aspectos y generar propuestas alternativas acerca de las diferentes manifestaciones culturales en el trabajo de piedras preciosas o semipreciosas" (MONTERROSA, 2018: 142).

La Arqueología Experimental es la replicación de los objetos lapidarios para conocer e imitar los posibles procesos y tiempos empleados en la manufactura de los objetos arqueológicos. Es imprescindible tomar en consideración la importancia que tiene la adecuada selección de materiales acorde con los mismos que había en el contexto y momento de la sociedad que se estudia y aunque las técnicas y materiales no tengan que ser estrictamente auténticos en su totalidad, sí deben serlos aquellos a partir de los cuales se hacen hipótesis (ASCHER, 1961: 809; MIRAMBELL, 1994: 109; MONTERROSA, 2018: 143).

Derivado de lo anterior, la presente investigación forma parte del proyecto "Estilos y Tradiciones Tecnológicas del México Antiguo", dirigido por el Dr. Emiliano Melgar Tísoc en el Museo de Templo Mayor en la Ciudad de México cuya base para generar conocimiento es la Arqueología Experimental y, por lo tanto, para este estudio se llevaron a cabo diferentes experimentos tomando en cuenta las técnicas, métodos, herramientas y materias primas empleados por diferentes grupos humanos mesoamericanos (véase MELGAR, 2004). 
A continuación, se presenta la Tabla 2 donde se muestran algunos de los experimentos llevados a cabo en esta investigación, los cuales, forman parte del Taller de Lapidaria acotado al proyecto mencionado antes. El primer experimento en llevarse a cabo fue la réplica de la tecnología zapoteca (véase MELGAR et al., 2010) (desgaste con laja de basalto, pulido con la misma herramienta adicionando arena humedecida, bruñido con un trozo de piel y corte e incisión con lascas de pedernal).
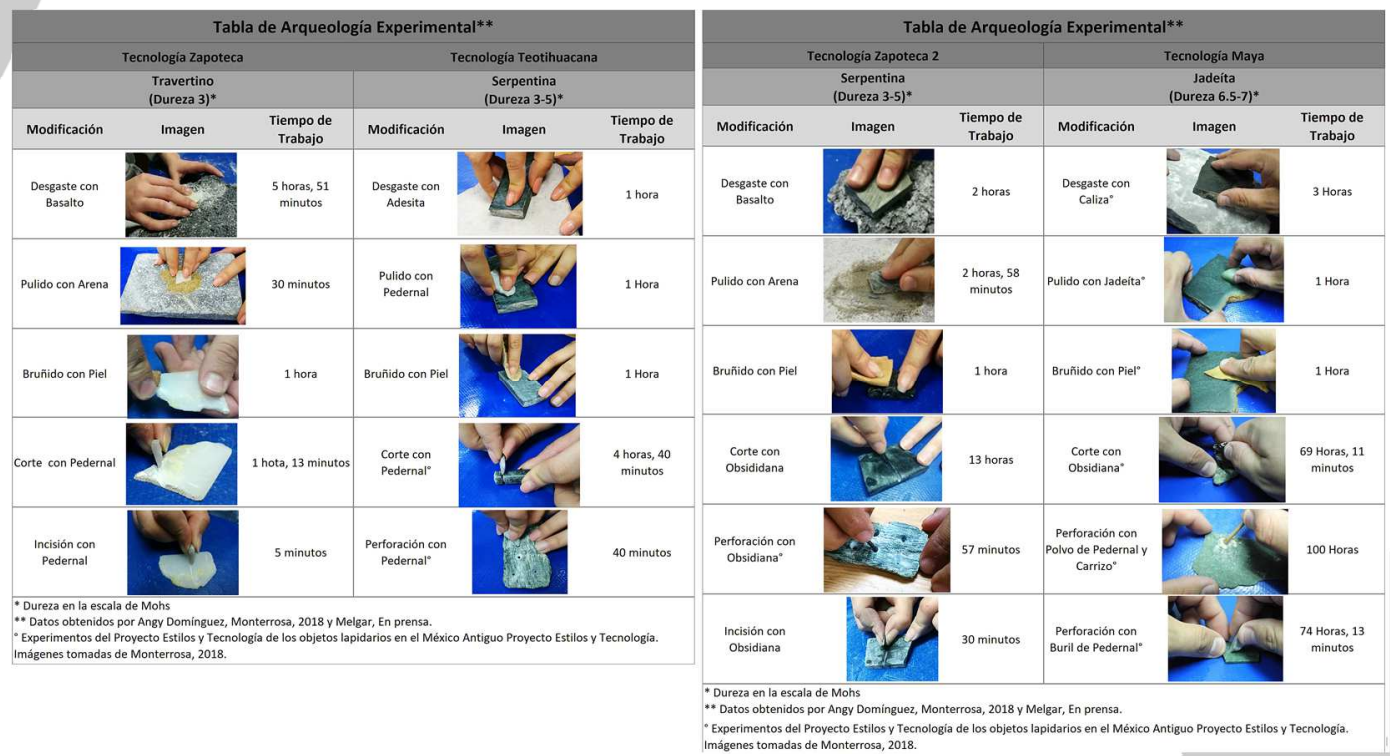

Tabla 2. Experimentos. 
En el segundo experimento se recreó la misma tecnología, pero con la variante de la serpentina como materia prima y obsidiana para los cortes (Tabla 2) ya que, de acuerdo con las investigaciones de Emiliano Melgar, Reyna Solís y Ernesto González (2010), la obsidiana se empleaba en los contextos de producción de los objetos consumidos por la élite de Monte Albán, mientras que el pedernal se utilizó para la manufactura lapidaria de los artefactos que usaba y consumía el resto de la población.

Las tecnologías maya y teotihuacana forman parte de la base de datos y de experimentos previamente realizados en el Taller de Lapidaria por lo que se recurrió a los datos obtenidos por Hervé Monterrosa (2018) para la tradición tecnológica de las Tierras Bajas Mayas (Petén), la cual se muestra en la Tabla 2.

En seguida, se describen las modificaciones llevadas a cabo a partir de la Arqueología Experimental:

A. Degastes. El desgaste es la modificación de la superficie de un objeto con el fin de adelgazarla o aplanarla a partir del frotamiento de las piezas con movimientos de vaivén alterno sobre herramientas líticas (lajas o metates), empleando, opcionalmente, agua como refrigerante y abrasivos como arena humedecida, polvo de pedernal, entre otros elementos que aceleraban el desgaste (SOLÍS, 2015: 108). La función del desgaste es obtener la forma preliminar o preforma del objeto que se busca elaborar.

Las marcas que resultaron del desgaste experimental con laja fueron rayones rectos bien definidos entrecruzados y una superficie irregular sobre todo en los materiales de menos dureza como el travertino donde son más evidentes; en contraste con otros experimentos donde se empleó arena como abrasivo en el que las superficies muestran rayones más finos 
y difusos, una textura regular y pulida (MONTERROSA, 2018: 156). Los tiempos establecidos para cada experimento y modificación se pueden observar en la Tabla 2.

B. Cortes Algunos cortes se pueden presentar de manera transversal o longitudinal mediante herramientas líticas como lascas de pedernal u obsidiana. Se emplean, opcionalmente, abrasivos cuando se usan tiras de piel o fibras vegetales como ixtle o el henequén, las cuales se tensan en un arco y con movimientos de vaivén alternos realiza un corte (MELGAR, 2011). Los cortes experimentales se llevaron a cabo empleando lascas de obsidiana y pedernal sobre travertino, serpentina y jadeíta (Tabla 2). Durante el proceso de trabajo, las lascas tuvieron que cambiarse constantemente debido a que van perdiendo el filo o bien, se procedió a reavivarlo, aunque esto ralentizó el proceso. Las huellas obtenidas forman un perfil anguloso en forma de "V" y rayones muy marcados y, en ocasiones, a causa de la presión la pieza se rompe y deja un reborde en la línea del corte (Tabla 2). Lo anterior contrasta con la forma redondeada o en "U" que resulta de los cortes hechos con tiras de piel o fibras vegetales y abrasivo (SOLÍS, 2015: 109-110; MONTERROSA, 2018: 157).

C. Perforaciones. Las perforaciones se dividen en tres: las cónicas, bicónicas y tubulares. Las primeras presentan un perfil circular cuyo diámetro va disminuyendo hacia el interior del objeto debido a que el perforador tiene una forma cónica. Las bicónicas, se forman a partir de dos perforaciones cónicas encontradas, es decir, que se encuentran en el centro del objeto y, las tubulares que presentan una planta circular con un diámetro uniforme y paredes rectas. Para las perforaciones se emplearon movimientos rotatorios alternos, agua como refrigerante y, en algunos casos, arena, polvo de pedernal o de obsidiana como abrasivos (los cuales se emplean cuando la herramienta es un trozo de carrizo (MONTERROSA, 2018: 160) (Tabla 2). En el caso de la presente colección, se encontraron los tres tipos de perforaciones. 
Una vez realizados los experimentos, se observó que las perforaciones hechas con herramientas líticas dejan rayones concéntricos nítidos que se aprecian simple vista, mientras que en los que emplearon abrasivos, presentaron líneas finas poco perceptibles y en la jadeíta, se observa una apariencia sutilmente brillante (MONTERROSA, 2018: 160).

D. Incisiones. Las incisiones se realizan a partir del mismo principio que los cortes, no obstante, no se llega a cortar el objeto, esto quiere decir que se emplean herramientas líticas, en este caso de obsidiana y pedernal, y, mediante movimientos de vaivén alternos sobre la materia prima (serpentina, travertino y jadeíta) se hace una acanaladura de poca profundidad. La función de las incisiones es crear diseños sobre la superficie de los objetos a modo de bajorrelieves (MONTERROSA, 2018: 160-161).

E. Acabado de Superficie: Pulido y Bruñido. El acabado de superficie se realiza a través de tres diferentes técnicas: pulido, bruñido y la combinación de ambas sobre la superficie de un objeto previamente desgastadas. El pulido tiene como objetivo desvanecer las huellas de trabajo de etapas anteriores como, por ejemplo, los rayones generados por el desgaste, el corte o la perforación mientras que el propósito del bruñido es abrillantar las superficies (MONTERROSA, 2018: 162). En el caso de las piedras verdes de Tlailotlacan, todas las piezas presentan pulido y la mayoría bruñido de mediana calidad, a excepción de las piezas en proceso de trabajo y la materia prima.

Los experimentos realizados consisten en el pulido con arena y basalto de un fragmento de serpentina y otro de travertino, pulidos de serpentina con nódulo de pedernal y pulidos de jadeíta con nódulo de jadeíta, donde el movimiento consistió en un vaivén alterno o movimientos circulares, dependiendo de la estructura del objeto que se trabajó. Por otro lado, los bruñidos se llevaron a cabo con un trozo de 
piel para todos los experimentos, se trabajó en seco y con movimientos de vaivén alterno (Tabla 2).

A continuación, se presentan las diferentes técnicas empleadas para la identificación de la materia prima y de los posibles yacimientos (fluorescencia de luz ultravioleta, Espectroscopía por dispersión de Energía de Rayos X (EDS) y Espectroscopía Micro Raman) y las usadas para observar e identificar las huellas de manufactura tanto de los experimentos descritos antes como de las piezas arqueológicas.

Para la observación de huellas de manufactura se empleó el mismo Microscopio Electrónico de Barrido (MEB) con los mismos parámetros que en la Espectroscopía por Dispersión de Energía de Rayos X. Las imágenes obtenidas con el MEB son en escala de grises debido a que funciona con electrones y no con luz.

El método empleado para agilizar el proceso de análisis de huellas de manufactura fue a partir de la elaboración de réplicas de la superficie de las piezas. Estas réplicas se hicieron a partir de un pequeño fragmento de polímero reblandecido con una gota de acetona de un gotero capilar, que se presiona contra la superficie del objeto y, al evaporarse la acetona, el elastómero recupera su rigidez original y queda impreso el negativo de las huellas. Posteriormente, se recubrieron con iones de oro para que el haz de electrones que barre la superficie del objeto proporcione información sobre su morfología: topología, rugosidad, porosidad y tamaño de las partículas (LÓPEZ, 2011: 47, 110; MELGAR et al., 2012a: 249). El proceso anterior se 
denomina sputtering y se lleva a cabo para mejorar a conductividad de los electrones. Cabe mencionar que las piezas arqueológicas no pueden recubrirse con iones de oro, por lo cual, se recurre a este tipo de técnica (MONTERROSA, 2018: 153). Debido al tamaño de los polímeros, que es bastante pequeño, se pueden introducir al MEB hasta 20 muestras a la vez, lo que reduce el tiempo.

\section{CONCLUSIONES}

Gracias al conjunto de técnicas arqueométricas no destructivas empleadas en esta investigación se pudieron identificar cuatro tipos de piedras verdes empleadas en Tlailotlacan, Teotihuacán: jadeíta, serpentina, cuarzo y travertino. De los 26 objetos, once son Cuarzos, es decir, el $42.3 \%$ del total, aunque, 4 de estas piezas son de un cuarzo identificado como procedente de Chiapas por lo que, de alguna manera, aunque sustituían la preciada jadeíta como jades culturales, éstos no eran propios de la región. No ha sido posible identificar la procedencia del resto de los cuarzos, aunque es posible que procedieran de yacimientos ubicados en Guerrero, Oaxaca, Puebla o, incluso, Guatemala donde se han registrado yacimientos de cuarzo.

La jadeíta se encontró en 8 objetos, es decir, el 30.7\% de los mismos, siendo la segunda materia prima más abundante de la colección, lo que resulta interesante porque es un porcentaje mucho mayor del esperado originalmente al inicio de la investigación por tratarse de una materia prima de muy alto valor y escasa. Respecto a los yacimientos de jadeíta, Hervé Monterrosa (2018: 265) afirma que es un 
"mineral heterogéneo y escaso que se da bajo condiciones específicas y, en consecuencia, sus yacimientos están muy localizados, tal como ocurre en el caso de Mesoamérica dónde la única fuente conocida hasta la fecha es el valle del río Motagua, en Guatemala".

En tercer lugar, se ubican los objetos de serpentina con 5 de 26 piezas, esto es el 19. $2 \%$, lo cual, resultó notable porque inicialmente se pensó que la colección estaba conformada en su mayoría por serpentinas debido al análisis visual preliminar. Como se vio en el apartado 5.7 del Capítulo V, todas las piezas de esta materia prima proceden de Tehuitzingo, Puebla, de acuerdo con la comparación con los Espectros de referencia. En último lugar están 2 esferas de travertino que representan el $7.7 \%$ del $100 \%$, cuyas intensidades Raman son muy distintas a las de la muestra de Tecali, Puebla, lo que indica que pertenecen a yacimientos diferentes que aún no han sido identificados.

También se pudo registrar la presencia de tres tecnologías: teotihuacana, zapoteca (de Monte Albán) y maya (Tierras Bajas Mayas). La mayoría de los artefactos son piezas cuyo estilo es muy general (a excepción de la prótesis dental y la placa incisa), por ejemplo, abundan las cuentas cuya presencia se hace notar en cualquier grupo humano mesoamericano, por lo que resultó imprescindible el uso de una metodología que permitiera ir más allá del aspecto morfológico de los objetos, esto es: observar e identificar las huellas y con esto las herramientas empleadas en el proceso de manufactura, a partir de la toma de huellas con réplicas de polímeros de 
la superficie de los artefactos para observarlas en el Microscopio Electrónico de Barrido.

Conforme a lo anterior, los materiales de cuarzo presentaron una manufactura zapoteca y teotihuacana principalmente, mientras que en los cuarzos chiapanecos predomina la zapoteca, cuya característica es el desgaste con basalto y pulidos con arena; los cortes e incisiones se realizaron con obsidiana o pedernal (dependiendo de la esfera social que producía y consumía los artefactos). No obstante, la mayoría de los objetos en esta colección son cuentas que no exhiben ninguna decoración, por lo que sólo se tomó en cuenta las dos primeras modificaciones. De acuerdo con lo anterior, se asumió que, de los objetos de cuarzo, 4 llegaron ya manufacturados y de los restantes solo llegó la materia prima a Teotihuacan, donde fueron manufacturados (a excepción de un objeto que sólo es materia prima sin ninguna modificación).

De las 8 piezas de jadeíta, seis presentaron manufactura maya que se caracteriza por desgastes con caliza, pedernal u obsidiana (dependiendo de la región) para los cortes e incisiones, buriles de pedernal o polvo de éste mismo y carrizo para las perforaciones y nódulos de jadeíta para pulir. Esta cadena operativa coincide con lo que se identificó en la colección. Esto permitió asumir que tuvieron un acceso relativamente restringido, empero, pudieron adquirir importantes piezas mayas (considerando el porcentaje elevado con relación a las otras dos materias primas) o bien, la movilidad de personas trajo consigo el traslado de estos objetos como pertenencias, lo cual se aclarará más adelante. 
En lo que se refiere a los objetos de serpentina, cuatro de cinco fueron manufacturados localmente (a excepción de uno cuya tradición tecnológica no pudo ser identificada), lo que sugiere que los tlailotlacanos tuvieron acceso a este material gracias a las redes de intercambio teotihuacanas locales y foráneas. Cabe mencionar que las piezas localizadas en Tlailotlacan debieron haber sido manufacturadas en alguno de los talleres de Teotihuacán ya que en este vecindario no hay evidencia de algún taller lapidario que se dedicara parcial o permanentemente a dicha actividad.

Algo igualmente notable, fueron las dos esferas de travertino, cuya procedencia no se identificó, aunque, pudieran provenir de alguno de los yacimientos de Puebla, como Tepeji de Rodríguez o de Oaxaca. Sin embargo, la manufactura de ambas es zapoteca, lo que indica que la materia prima se desplazó desde alguno de los yacimientos mencionados hasta los Valles Centrales de Oaxaca donde fueron manufacturadas y posteriormente trasladados los objetos terminados a Tlailotlacan. Por otro lado, está una cuenta de jadeíta en la que se identificó un desgaste llevado a cabo con arenisca, lo que convierte a este pieza en la única con esta modificación, la cual es común en el área Olmeca del preclásico (MELGAR, 2019: comunicación personal), aunque también se ha reportado el uso de lajas de arenisca en Chiapa de Corzo, los objetos de jade azul de Templo Mayor también lo presentan y en Tabasco y Campeche, en sitios como Moral Reforma, Comalcalco, Calakmul y Jaina (MONTERROSA, 2018: 199).

Vinculado a lo anterior se encuentra la cuestión de las redes de interacción interregional que expliquen cómo los objetos foráneos terminaron en Tlailotlacan. 
Sin embargo, este tema sale de los límites del presente artículo que forma parte de una investigación en proceso que aborda no solo la temática tecnológica, sino también un poco de esta línea sobre los circuitos y redes de interacción e intercambio.

Como se pudo observar en este texto, es importante la colaboración interdisciplinaria en la arqueología para enriquecer las investigaciones y de esta manera profundizar en el conocimiento que se tiene sobre las sociedades pretéritas. Así mismo, es primordial trascender la mera recopilación de datos duros que nos proporcionan las técnicas arqueométricas para poder alcanzar el fin último de la arqueología que es conocer y entender las distintas dinámicas sociales de las sociedades del pasado.

\section{REFERENCIAS BIBLIOGRÁFICAS}

ASCHER, R. 1961 "Experimental Archaeology". American Anthropologist vol. 63 (4), 793-816.

BRANIFF, B. 1995. "La frontera septentrional de Mesoamérica". En L. Manzanilla y L. López (eds.). Historia Antigua de México. Tomo I. El México antiguo, sus áreas culturales, los orígenes y el horizonte preclásico. México: Porrúa, 113-143.

CASTAÑóN, M. 2014. Cambios en la introducción y distribución de los materiales foráneos a través de las diferentes fases cronológicas de Teotihuacán: Lapidaria, cerámica y concha. Tesis de Maestría en Antropología. Universidad Nacional Autónoma de México.

CONKEY, M. 1978. "Style and information in cultural evolution: toward a predictive model for the paleolithic". En C. Redman, W. Langhorne, M. Bernan, N. Versaggi, E. 
Curtin y J. Wanser (eds.). Social archaeology. Beyond subsistence and dating. New York: Academic Press, 61-85.

DOMÍNGUEZ, A. 2015 Caracterización cultural y diferenciación jerárquica de los habitantes de Tlailotlacan, Teotihuacán, a través del análisis comparativo de ofrendas riuales. Tesis de Licenciatura. Escuela Nacional de Antropología e Historia.

FAHMEL, B. 1995. "Monte Albán y Teotihuacán dentro del proceso civilizatorio mesoamericano". Anales de Antropología vol. XXXII (32), 101-119.

GÁZQUEZ, F., F. RULL, J. CALAFORRA, E. GUIRADO, A. SANZ, J. MEDINA, C. DE LAS HERAS, A. PRADA y J. LASHERAS. 2014. "Análisis no destructivo e in situ de minerales y pigmentos en cuevas mediante espectroscopia Raman". En J. Calaforra y J. Durán (eds.). Primer Congreso Iberoamericano y Quinto Congreso Español sobre Cuevas Turísticas. Aracena, España: Cuevatur, 297-306.

GAZZOLA, J. 2005. "La producción lapidaria en Teotihuacán, estudio de las actividades productivas en los talleres de un conjunto habitacional". En M. Ruiz y J. Torres (eds.). Memoria de la Tercera Mesa Redonda de Teotihuacán. Arquitectura y Urbanismo: Pasado y presente de los espacios en Teotihuacán. México: Instituto Nacional de Antropología e Historia, 841-878.

GAZZOLA, J. 2007. "La producción de cuentas en piedras verdes en los talleres lapidarios de La Ventilla, Teotihuacán". Arqueología 36,52-70.

GAZZOLA, J. 2009. "La cadena operativa en la fabricación de máscaras en los talleres de lapidaria de La Ventilla, Teotihuacán". En L. González y L. Mirambell (eds.). Reflexiones sobre la industria lítica. México: Instituto Nacional de Antropología e Historia, 61-77.

GONZÁLEZ, G. 2001. Mineralogía y petrología de las serpentinas del cuerpo ultramáfico de Tehuitzingo, Edo. de Puebla. Tesis de Maestría en Ciencias Geoquímica y Petrología. Universidad Nacional Autónoma de México.

LÓPEZ, J. 2011. Estudio de los artefactos de pizarra recuperados en contextos rituales de Teotihuacán. Procedencia, producción lapidaria y distribución. Tesis de Maestría en Estudios Mesoamericanos. Universidad Nacional Autónoma de México.

MELGAR, E. 2004. Proyecto La Lapidaria del Templo Mayor: Estilos y tradiciones tecnológicas. México: Archivo del Museo del Templo Mayor. 
MELGAR, E. 2006. Análisis de huellas de manufactura de la lapidaria de Teopancazco y Xalla, Teotihuacán. México: Archivo del Museo del Templo Mayor.

MELGAR, E. 2011. Estilo y tecnología de los objetos lapidarios en el México antiguo. México: Archivo del Museo del Templo Mayor.

MELGAR, E. 2014. Comercio, tributo y producción de las turquesas del Templo Mayor de Tenochtitlan. Tesis de Doctorado. Universidad Nacional Autónoma de México.

MELGAR, E. 2017 "Manufacturing Techniques of Greenstone Mosaics from Teotihuacan and Palenque". En R. Alonso, D. Canales, y J. Baena (eds.). Playing with the time. Experimental Archaeology and the study of the past. Madrid: Editorial Castilla y León, 119-124.

MELGAR, E. y C. ANDRIEU. 2016 "El intercambio de jade en las Tierras Bajas mayas desde una perspectiva tecnológica". En B. Arroyo, L. Méndez y G. Ajú (eds.). Investigaciones Arqueométricas recientes de los objetos prehispánicos de concha y lapidaria en México y Guatemala. Simposio de Investigaciones Arqueológicas de Guatemala. Guatemala: Museo de Arqueología de Guatemala, 1065-1076.

MELGAR, E. y M. DOMÍNGUEZ. 2014. "Los artesanos de concha y la élite de Calakmul: Los objetos elaborados y sus técnicas de manufactura". Encuentro internacional. Los investigadores de la cultura maya 2013, vol. 22, 203-219.

MELGAR, E.; E. GALLAGA y R. SOLÍS. 2014. "La pirita y su manufactura: análisis de cuatro contextos mesoamericanos". Estudios de cultura maya vol. 43, 41-68.

MELGAR, E. y R. SOLÍS. 2008. "Usos de la luz UV en los objetos lapidarios". Suplemento Cultural El Tlacuache, 4.

MELGAR, E. y R. SOLÍS. 2010. "Los artistas del jade en Mesoamérica y China: Una comparación tecnológica". En L. Chen y A. Saladino (eds.). La Nueva Nao: De Formosa a América Latina. Taipei: Universidad de Tamkang, 379-396.

MELGAR, E. y R. SOLÍS. 2018. "Caracterización mineralógica y tecnológica de la lapidaria de Teopancazco". En L. Manzanilla (ed.). Teopancazco como centro de barrio multiétnico de Teotihuacán. México: Instituto de Investigaciones AntropológicasUniversidad Nacional Autónoma de México, 621-672. 
MELGAR, E., R. SOLÍS y E. GONZÁLEZ. 2010. "Producción y prestigio en concha y lapidaria de Monte Albán". En E. Melgar, R. Solís y E. González (comps.). Producción de bienes de prestigio, ornamentales y votivos de la América Antigua. Miami: Syllaba Press, 6-21.

MELGAR, E., R. SOLÍS y E. GONZÁLEZ. 2018. "Análisis tecnológico de objetos en concha y lapidaria de Monte Albán". En E. Melgar y L. Manzanilla (eds.). Arqueología de la Producción. México: Instituto Nacional de Antropología e Historia-Universidad Nacional Autónoma de México, 91-122.

MELGAR Tísoc, E. y R. SOLÍS Ciriaco. 2016. "Objetos mayas de jadeíta en el Templo Mayor de Tenochtitlan". Arqueología Mexicana 140, 81-85.

MELGAR, E.; R. SOLÍS y H. MONTERROSA. 2018. Piedras de fuego y agua. Turquesas y jades entre los nahuas. México: Museo del Templo Mayor, Instituto Nacional de Antropología e Historia y Museo de Geología, Universidad Nacional Autónoma de México.

MELGAR, E., R. SOLÍS y J. RUVALCABA. 2012a. "La lapidaria de Teopancazco: composición y manufactura". En L. Manzanilla (ed.). Estudios arqueométricos del centro de barrio de Teopancazco en Teotihuacán. México: Instituto de Investigaciones Antropológicas, Universidad Nacional Autónoma de México, 241-268.

MELGAR, E., R. SOLÍS y J. RUVALCABA. 2012b. "Lapidaria de Tamtoc". En G. Córdova, E. Martínez y P. Hernández (eds.). Tamtoc. Esbozo de una antigua sociedad urbana. México, Instituto Nacional de Antropología e Historia, 331-354.

MIRAMBELL, L. 1994. "Fundamentos sobre el estudio de huellas de uso en materiales líticos arqueológicos". Anales de Antropología vol. 31, 105-131.

MONTERROSA, H. y E. MELGAR. 2017a. "La presencia maya en el Templo Mayor. Una aproximación de la jadeíta verde en las ofrendas del Huey Teocalli de Tenochtitlan". En M. Domínguez, M. Gallegos, R. Armijo y M. León (eds.). Los investigadores de la cultura maya. El comercio y otros temas. Campeche: Universidad Autónoma de Campeche, 215229.

MONTERROSA, H. y E. MELGAR. 2017b "Reliquias mayas y olmecas de jadeíta en el Templo Mayor de Tenochtitlan". En B. Arroyo, L. Méndez, y G. Ajú (eds.). XXX Simposio de investigaciones arqueológicas en Guatemala. Guatemala: Ministerio de Cultura y Deportes, Asociación Tikal, 905-916. 
ORTEGA, V. 2014. La presencia oaxaqueña en la ciudad de Teotihuacán durante el clásico. Tesis de doctorado. Universidad Nacional Autónoma de México.

PÉREZ, A. 2016. La ofrenda de turquesa en el templo prehispánico del monte Tláloc. Tesis de Licenciatura en Arqueología. Escuela Nacional de Antropología e Historia.

RATTRAY, E. 1973. The Oaxaca Barrio at Teotihuacan. Monografías Mesoamericanas 1. México.

RATTRAY, E. 2009. "Nuevos fechamientos por radiocarbono en Teotihuacán y sus correlaciones con otras regiones de Mesoamérica". En A. Daneels (ed.). Cronología y periodización en Mesoamérica y el Norte de México. V Coloquio Pedro Bosch Gimpera. México: Universidad Nacional Autónoma de México, 139-147.

SACKETT, J. 1977. "The meaning of style in archaeology: a general model". American Antiquity. vol. 42 (3), 369-380.

SELLET, F. 1993 "Chaine Operatoire. The concept and its applications". Lithic Technology vol. 18 (1-2), 106-111.

SOLÍS, R. 2015. Esferas de producción y consumo de objetos lapidarios en las estructuras aledañas del Templo Mayor de Tenochtitlan. Tesis de Doctorado en Antropología. Universidad Nacional Autónoma de México.

SPENCE, M. 1992. "Tlailotlacan, a zapotec enclave in Teotihuacán". En J. Berlo (ed.). Art, ideology, and the city of the Teotihuacan, A symposium at Dumbarton Oaks 8th and 9th october 1988. Washington D.C.: Dumbarton Oaks Research Library and Collection, 59-88.

TURNER, M. 1992. "Style in Lapidary Technology: Identifying the Teotihuacan Lapidary Industry". En J. Berlo (ed.). Art, Ideology and the City of Teotihuacan. Washington D.C.: Dumbarton Oaks, 89-112.

UNIVERSIDAD COMPLUTENSE DE MADRID. n. d. "Espectroscopia Raman". En Centro de Asistencia a la Investigación de Arqueometría y Análisis Arqueológico. Facultad de Geografía e Historia, Universidad Complutense de Madrid. Disponible en: http://pendientedemigracion.ucm.es/info/arqueoanalisis/Service\%201.3.2.htm Consultado el 20 de Febrero del 2017.

WALKER, J. 1991. "Jade: A Special Gemstone. The Gemology of Jade". En R. Keverne (ed.). Jade. Eastbourne: Springer Science \& Business Media, 19-41. 


\section{Clio Arqueológica 2020, V35N2, p.29-77, DOMINGUEZ}

DOI: 10.20891/clio.V35V2p29-77

WILLEY, G. y P. PHILLIPS. 1958. Method and theory in American archaeology. Chicago: University Chicago Press.

WOBST, M. 1977. "Stylistic Behavior and Information Exchange". En C. Cleland (ed.). Anthropological Papers 61. Michigan: Museum of Anthropology, University of Michigan, 317-342. 